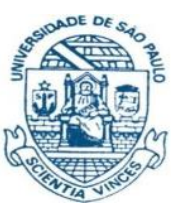

UNIVERSIDADE DE SÃO PAULO

INSTITUTO DE PSICOLOGIA

PROGRAMA DE PÓS-GRADUAÇÃO EM PSICOLOGIA EXPERIMENTAL

Guilherme do Espirito Santo Paes

EFEITO DA PRIVAÇÃO DE ALIMENTO SOBRE A DESVALORIZAÇÃO PELO ATRASO EM UMA TAREFA DE ESCOLHA ALOMÓRFICA

SÃO PAULO

2019 
UNIVERSIDADE DE SÃO PAULO

INSTITUTO DE PSICOLOGIA

PROGRAMA DE PÓS-GRADUAÇÃO EM PSICOLOGIA EXPERIMENTAL

Guilherme do Espirito Santo Paes

\section{EFEITO DA PRIVAÇÃO DE ALIMENTO SOBRE A DESVALORIZAÇÃO PELO ATRASO EM UMA TAREFA DE ESCOLHA ALOMÓRFICA}

Dissertação de mestrado entregue ao programa de pós-graduação em Psicologia Experimental, como parte dos requsitos para obtenção do título de mestre .

Área de concentração: Psicologia experimental

Orientador(a): Prof ${ }^{a}$ Dra. Miriam Garcia Mijares. 


\section{AUTORIZO A REPRODUÇÃO E DIVULGAÇÃO TOTAL OU PARCIAL DESTE TRABALHO, POR QUALQUER MEIO CONVENCIONAL OU ELETRÔNICO, PARA FINS DE ESTUDO E PESQUISA, DESDE QUE CITADA A FONTE.}

Catalogação na publicação Biblioteca Dante Moreira Leite Instituto de Psicologia da Universidade de São Paulo Dados fornecidos pelo(a) autor(a)

\section{Do Espirito Santo Paes, Guilherme}

Efeito da privação de alimento sobre a desvalorização pelo atraso em uma tarefa de escolha alomórfica / Guilherme Do Espirito Santo Paes; orientadora Miriam Garcia Mijares. -- São Paulo, 2019.

$75 \mathrm{f}$.

Dissertação (Mestrado - Programa de Pós-Graduação em Psicologia Experimental) -Instituto de Psicologia, Universidade de São Paulo, 2019.

1. desvalorização pelo atraso. 2. privação de alimentos. 3. wistar. 4. escolha. 5. roda de atividades. I. Garcia Mijares, Miriam, orient. II. Título. 
Nome: Guilherme do Espirito Santo Paes

Título: Efeito da privação de alimento sobre a desvalorização pelo atraso em uma tarefa de escolha alomórfica

Dissertação de mestrado apresentada ao Programa de Pós-graduação em Psicologia Experimental (PSE) do Instituto de Psicologia da Universidade de São Paulo (IPUSP) como requisito para a obtenção do título de mestre.

Área de concentração: Psicologia Experimental.

Aprovado em:

Banca examinadora:

Profa Dra.

Instituição:

Assinatura

Prof. Dr.

Instituição:

Assinatura

Prof. Dr.

Instituição:

Assinatura

Prof. Dr.

Instituição:

Assinatura 
Dedicada à minha mãe, Joana, e ao meu pai, Amauri 


\section{Agradecimentos}

Antes de tudo, gostaria de agradecer à Miriam. Primeiro por me ensinar, desde a graduação, o valor de conhecer a Análise do Comportamento de forma rigorosa e, ao mesmo tempo, procurar conhecer seus fundamentos e limites e superá-los, entendendo e respeitando o conhecimento produzido em outras áreas de conhecimento. Segundo, por ser uma orientadora que sempre lembra e leva em conta o fato de que quem faz pesquisa, no fim das contas, são seres humanos. Finalmente, por abrir as portas do laboratório para mim, confiando em um projeto de pesquisa meio maluco e sendo uma orientada cujas observações, sugestões e apontamentos foram não só fundamentais, mas também como fonte de ânimo nos momentos mais confusos da condução da pesquisa.

Ao Andeson, que, com muita generosidade, foi uma espécie de "padrinho" desse projeto, ajudando com várias das inúmeras dificuldades esperadas e inesperadas que se multiplicavam ao longo da pesquisa e, às vezes sem saber, foi acolhedor quando eu ficava desesperado (com ou sem razão!). Te devo bem mais que $\mathrm{R} \$ 50,00$ !

Aos meus pais, meio que por absolutamente tudo, já que, sem a ajuda e presença deles, não teria sido possível realizar esse mestrado, mas principalmente pelo amor, pela paciência e por todo suporte emocional e logístico que vocês me deram. Se esse trabalho tem qualidades, elas são dedicas a vocês com todo o meu amor e minha gratidão!

À Laura! Se já é preciso muita paciência para conviver comigo normalmente, que dirá nos momentos mais tensos ao longo da pesquisa, mas, mesmo assim, você foi e tem sido uma das pessoas mais pacientes, compreensivas, carinhosas e acolhedoras que conheci. Obrigado por todo amor que você tem me dado!

Aos meus queridos amigos pela paciência, interesse, acolhimento e incentivo ao longo da pesquisa. Em especial ao Gustavo, à Tilie, ao Heitor e à Lígia, pelos momentos de loucura e de calma compartilhados ao longo desses anos, pelas cervejas, séries, conversas, planos intermitentes de largar a psicologia, jogatinas de lolzinho e todo o resto. Vocês são de ouro!

Às pessoas com que pude conviver e das quais pude me aproximar ao longo desses três anos de mestrado, principalmente ao Edu e ao César, pelos boardgames, pães de 
queijo, conversas sobre ciência e Análise do Comportamento e pelo companheirismo ao longo das aulas e dias de experimento.

Aos meus colegas de laboratório - Alceu, Aline, Carioca, Liane, Luiz, Rodrigo, William, Yulla - pelas discussões e conversas, pelos grupos de estudo, por todas as risadas e cafés nas reuniões e pelo acolhimento ao longo das coletas e escritas da vida! Admiro muito todos vocês e agradeço por ter aprendido tanto sobre pesquisa e Análise do Comportamento com vocês ao longo desses anos.

Aos professores Fábio Leyser e Cristiano Coelho pela leitura muito atenta e criteriosa e pelas preciosas contribuições, correções e sugestões feitas no exame de qualificação, fundamentais para a realização e conclusão dessa pesquisa.

À Fátima, por toda a ajuda com documentos, relatórios, outras burocracias inomináveis e solução de diversas dúvidas que apareceram ao longo do caminho!

Ao CNPq pelo apoio financeiro na forma de bolsa de estudos concedida ao longo dos dois primeiros anos da realização desse trabalho. 
Num minuto cabe o tempo

De decisões e revisões que num minuto são o inverso.

T. S. Eliot, "A canção de amor de J. Alfred Prufrock"

Se deixamos de beber, morremos de sede; se deixamos de comer, morremos de fome, ele disse - é a essas sábias conclusões que chegam todos os aforismos, [...]. No deserto, ansiamos por água, é mais ou menos o que afirma a máxima de Pascal, ele disse, pensei. Se formos rigorosos, disse, o que nos fica dos grandes esboços filosóficos é apenas um ressaibo aforístico, seja qual for a filosofia ou o filósofo que escolhamos; tudo se esfarela, se o analisarmos com a plenitude de nossas faculdades, ou seja, com todos os nossos instrumentos intelectuais, disse, pensei.

Thomas Bernhard, "O Náufrago" 
Paes, G. E. S. (2019). Efeito da privação de alimento sobre a desvalorização pelo atraso em uma tarefa de escolha alomórfica. Dissertação de Mestrado. Universidade de São Paulo, Instituto de Psicologia, Programa de Pós-graduação em Psicologia Experimental.

\section{Resumo}

A literatura de escolha em Análise do comportamento enfatizara que o atraso é um dos fatores que influenciam o valor reforçador de um estímulo consequente. Quanto maior o atraso para apresentação de um estímulo, menor o seu valor e essa redução do valor reforçador de um estímulo é denominada "desvalorização". Quando a desvalorização ocorre em função do atraso, a literatura fala de "desvalorização pelo atraso". Os procedimentos frequentemente utilizados para estudar desvalorização pelo atraso envolvem a escolha entre duas ou mais alternativas, uma de pequena magnitude e outra de grande magnitude, e a manipulação do atraso com que elas são apresentadas. As situações de escolha entre o mesmo reforçador são denominadas como "isomórficas", já as que envolvem escolha entre reforçadores diferentes são chamadas de "alomórficas. Algumas pesquisas têm se preocupado em estudar os efeitos da privação sobre escolhas isomórficas e alomórfica em humanos, contudo, as pesquisas com animais não-humanos a respeito dos efeitos da privação sobre a escolha só foram realizadas em escolha isomórfica. O objetivo desse estudo foi investigar se o grau de desvalorização difere quando ratos Wistar realizam uma tarefa alomórfica de desvalorização pelo atraso em dois regimes de privação diferentes (alimento liberado 1 hora e 21 horas depois da sessão experimental), em que as alternativas são água com açúcar (atrasada) e acesso à roda de atividades (imediata). Seis ratos wistar passaram por um procedimento sistemático de desvalorização em que a alternativa com atraso teve como reforçador $0,01 \mathrm{ml}$ de solução de água com sacarose 7,5\% e a alternativa imediata consistiu em 30s de acesso à roda. Os atrasos utilizados foram $2 \mathrm{~s}, 4 \mathrm{~s}, 8 \mathrm{~s}$ e $16 \mathrm{~s}$. Cada atraso foi apresentada duas vezes, uma em cada condição de privação. A comparação entre as proporções de escolha pela solução de sacarose, das áreas sob a curva e das velocidades de correr na roda mostraram que a variação do atraso modificou de modo moderado os padrões de escolha. No entanto, não se verificou diferenças no efeito do atraso entre as condições de privação. Discutem-se a hipótese de que esse efeito moderado do atraso e a ausência de efeitos da privação se devam à configuração das alternativas, aos estímulos utilizados ou ao valor dos parâmetros de estímulo (como magnitude absoluta e atraso da alternativa de menor magnitude).

Palavras-chave: desvalorização pelo atraso, privação de alimento, Wistar, escolha, roda de atividades. 
Paes, G. E. S. (2019). Effect of food deprivation on delay discounting in an allomorphic choice task. Dissertação de Mestrado. Universidade de São Paulo, Instituto de Psicologia, Programa de Pós-graduação em Psicologia Experimental.

\begin{abstract}
The behavior analysis' choice literature emphasizes delay as one of the factors that influences the reinforcer value of a consequence. The longer the delay for the stimulus presentation, the lower its value, and this devaluation of the stimulus is called discounting. When the discounting occurs as a result of the delay, the literature calls it delay discounting. The most commonly used delay discounting procedures involve the choice between two alternatives, one with low magnitude and the other with high magnitude, and the delay manipulations with which they are presented. The choice situations between alternatives with the same reinforcing stimulus are called isomorphic, while the alternatives with different stimuli are called allomorphic. Some research studied the effects of deprivation on isomorphic and allomorphic choices with human subjects, however, the research with non-human subjects only studied the effects of deprivation on allomorphic choice situations. The purpose of these study was to investigate whether the degree of discounting differs when Wistar rats underwent an allomorphic discounting task in two food deprivation conditions (food delivered 1 hour and 21 hours after the experimental session), in which the alternatives were sucrose solution (delayed) and access to running wheel (immediate). Six Wistar rats underwent a systematic devaluation procedure in which the delayed alternative was reinforced with $0,01 \mathrm{ml} 7,5 \%$ sucrose solution, and the immediate alternative was reinforced with 30 s running wheel access. The delays with the sucrose solution was presented were $2 \mathrm{~s}, 4 \mathrm{~s}, 8 \mathrm{~s}$, and $16 \mathrm{~s}$. Each delay was presented twice, one in each deprivation condition. The comparison between the choice proportions for the sucrose solution, the area under the curve, and the wheel running rate showed the delay variation moderately affected the choice patterns. However, there was no effect of deprivation. It is argued that this moderate effect of the delays, and absence of deprivation effect may be a result of the alternative configuration, the stimuli used, or the parameters value (as absolute magnitude, and the delay of the low magnitude.
\end{abstract}

Keywords: delay discounting, food deprivation, Wistar, choice, activity wheel. 


\section{Sumário}

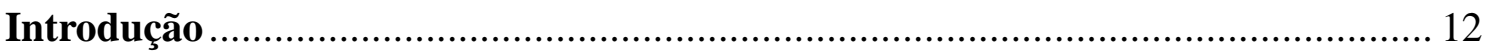

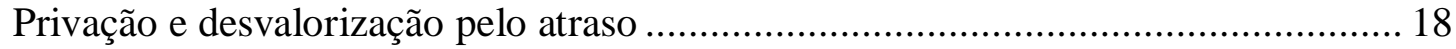

Correr na roda de atividades e consumo de solução de sacarose ............................... 32

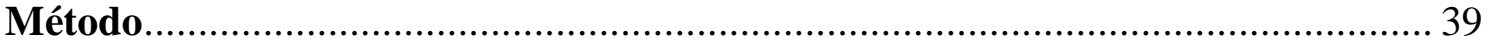

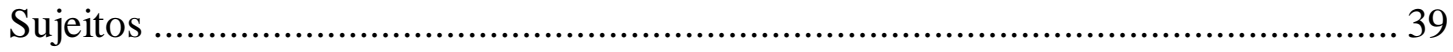

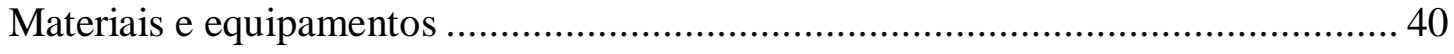

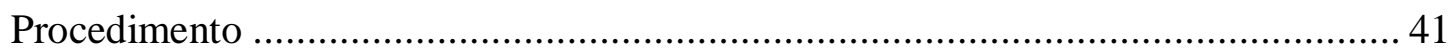

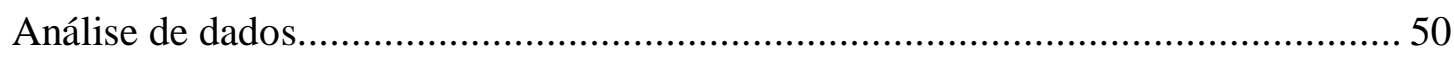

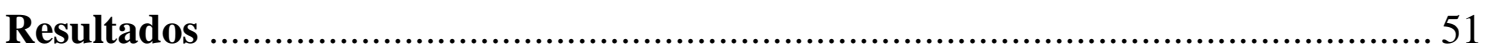

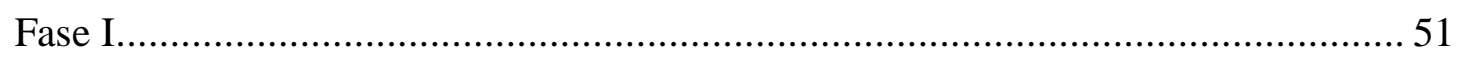

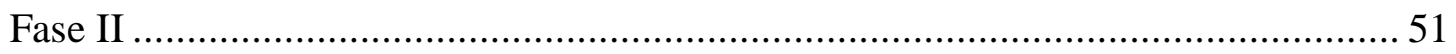

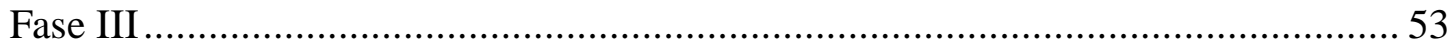

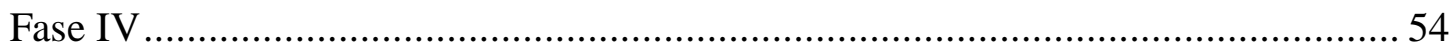

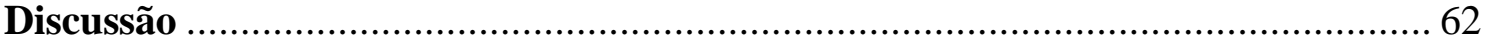

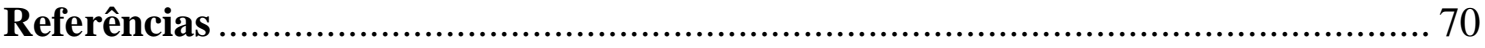

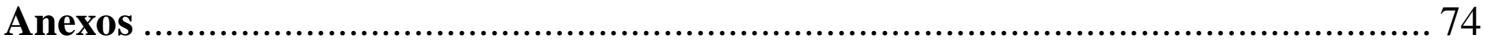


Trabalhos teóricos e experimentais sobre atraso de reforço (por exemplo, (Ainslie, 1974, 1975; Rachlin, 1974; Rachlin \& Green, 1972) deram fundamentação teórica e metodológica na Análise do Comportamento para o estudo de padrões comportamentais chamados de "Autocontrole," ou do seu inverso, "Impulsividade".

Ainslie (1975), Mazur (1987) e Rachlin (1974) enfatizaram que o atraso é um dos fatores que influenciam o valor reforçador de um estímulo consequente. Quanto maior o atraso para apresentação de um estímulo, menor o seu valor; A essa redução do valor reforçador de um estímulo denomina-se “desvalorização”. Quando a desvalorização ocorre em função do atraso, a literatura fala de "desvalorização pelo atraso" (no inglês delay discounting) (Gonçalves, 2005).

Os procedimentos frequentemente utilizados para estudar desvalorização pelo atraso envolvem a escolha entre duas ou mais alternativas, uma de pequena magnitude e outra de grande magnitude, e a manipulação do atraso com que elas são apresentadas. Esses procedimentos têm mostrado, como regra geral, que a escolha por reforçadores de pequena magnitude e imediatos aumenta conforme aumenta o atraso de reforçadores de grande magnitude (Green \& Myerson, 2004).

Parte das pesquisas sobre desvalorização pelo atraso tem tido como foco produzir modelos quantitativos para as possíveis relações entre o comportamento de escolha e o atraso do reforço. O estudo de Mazur (1987) é um marco importante nesse tipo de pesquisa, pois o autor desenvolveu um procedimento que permite que o atraso do reforço seja modificado dentro de uma sessão experimental de acordo com a escolha do sujeito, ao mesmo tempo que possibilita o teste da adequação de diferentes modelos matemáticos. Esse procedimento, denominado "ajuste do atraso", consiste em manipular o atraso para dispensar o reforçador de maior magnitude de acordo com as escolhas anteriores: se a alternativa que disponibiliza esse reforçador é escolhida duas vezes seguidas, o atraso 
aumenta; se a alternativa que disponibiliza o reforçador de menor magnitude é escolhido duas vezes seguidas, o atraso diminui. A manipulação do atraso é realizada até se obter pontos de indiferença, em que as duas alternativas (imediata e atrasada) são escolhidas com a mesma frequência, ou, na terminologia da área, em que têm o mesmo valor reforçador.

Após encontrar pontos de indiferença utilizando reforçadores imediatos de magnitudes diferentes, Mazur (1987) construiu e comparou curvas que denominou como "curvas de indiferença" ou "curvas de desvalorização", que consistiam na curva encontrada ao se construir o gráfico dos pontos de indiferença em função do atraso necessário para que as alternativas tivessem valores equivalentes. Ao comparar as curvas de indiferenças obtidas a partir dos dados com as curvas previstas pelos modelos matemáticos testados, observou que o mais adequado era o modelo de desvalorização hiperbólica, descrito pela equação 1:

$$
\mathrm{V}=\mathrm{A} /(1+\mathrm{kD})
$$

Na equação $1, V$ é o valor do reforçador apresentado, $A$ é sua magnitude e $D$ é o atraso da sua apresentação. A variável $k$ é um parâmetro livre e representa o grau de influência que o atraso (variável D) terá na desvalorização do valor do reforçador; quanto maior for $k$, maior será a influência do atraso na desvalorização. Portanto, o modelo prevê que o valor reforçador é inversamente proporcional ao atraso do reforço e, por apresentar aceleração negativa decrescente, que a variação no valor reforçador é maior quando os atrasos do reforço são pequenos.

Green e Myerson (2004), em uma revisão sobre a desvalorização pelo atraso, sugerem que o modelo descrito pela equação 2 seria mais adequado do que o descrito pela equação 1 , já que o acréscimo de uma variável que representa a possibilidade do efeito 
do atraso produzir mudanças não lineares no valor reforçador geraria curvas mais próximas das encontradas a partir dos dados empíricos.

$$
\mathrm{V}=\mathrm{A} /(1+\mathrm{kD})^{\mathrm{S}}
$$

$\mathrm{Na}$ equação 2, as variáveis são as mesmas que na equação 1, exceto a variável $s$, que indica que o efeito do atraso pode variar de forma não-linear (o que ocorre somente quando $s=1$ ). Tanto a variável $k$ quanto a variável $s$ são parâmetros livres, estimados com procedimentos de regressão não linear a partir dos dados empíricos obtidos.

Green e Myerson (2004), Odum, (2011) e Vanderveldt, Oliveira, e Green (2016), em suas revisões, apontam a generalidade do valor descritivo e preditivo do modelo hiperbólico da equação 2, listando e descrevendo experimentos que utilizaram espécies diferentes (humanos, ratos, macacos rhesus, chimpanzés, bonobos e camundongos) e diferentes tipos de reforçadores (água, água com sacarose, álcool, nicotina, cocaína, heroína, comidas diferentes, dinheiro e benefícios de saúde).

A produção de modelos matemáticos na área de autocontrole e impulsividade é importante porque aumenta a precisão da descrição da relação entre as variáveis analisadas e permite comparar os dados de pesquisas que usam procedimentos, sujeitos e estímulos diferentes (Green e Myerson, 2004; Odum, 2011; Vanderveldt, Olveira \& Green, 2016).

A comparação dos valores estimados dos parâmetros livres tem sido uma das formas de estabelecer relações entre o atraso e a escolha. Dentre os parâmetros livres da equação 2, a variável $k$ tem sido recebido especial atenção dos pesquisadores, por indicar, para cada organismo, qual o efeito do atraso na diminuição de seu valor reforçador (Odum, 2011). Sendo assim, valores altos de $k$ indicam que o organismo tende a priorizar as alternativas imediatas mesmo que haja atrasos pequenos na alternativa atrasada e 
valores baixos de $k$ indicam que é necessário que o atraso seja alto para que o organismo passe a priorizar a alternativa imediata. Estudos de psicofarmacologia (e.g., Evenden \& Ryan, 1996) são exemplos do uso da variável $k$ para comparar condições experimentais distintas, já que o valor de $k$ é estimado para as curvas de desvalorização obtidas antes e depois da intervenção farmacológica. Se há alteração no valor de $k$, argumenta-se que o fármaco altera o efeito do atraso no valor de cada alternativa.

Em geral, os experimentos que investigam a desvalorização pelo atraso fazem-no utilizando o mesmo tipo de reforçador em ambas as alternativas (Green e Myerson, 2004; Odum, 2011; Vanderveldt et al., 2016). Por exemplo, (Richards, Mitchell, de Wit, e Seiden (1997), em um estudo que utilizou um procedimento alternativo ao de Mazur (1987), denominado "ajuste de magnitude", conduziram um experimento em que ratos privados de água escolhiam entre uma alternativa que apresentava $10 \mu 1$ de água após um atraso fixo e outra que apresentava uma quantidade menor de água imediatamente. Se a alternativa imediata fosse escolhida duas vezes seguidas a quantidade de reforçador liberado era diminuída; se a alternativa com atraso fosse escolhida duas vezes, a quantidade do reforçador liberado na alternativa imediata é aumentada. Por outro lado, diversas situações de escolha no cotidiano ocorrem entre reforçadores distintos, apresentados com atrasos diferentes. Por exemplo, pode-se ter que optar entre as consequências de consumir álcool agora e as consequências de acordar cedo amanhã, ou entre comprar um par de sapatos agora ou comprar um carro daqui a um ano. As situações de escolha entre o mesmo reforçador são denominadas como "isomórficas", já as que envolvem escolha entre reforçadores diferentes são chamadas de "alomórficas" (Huskinson, Woolverton, Green, Myerson, \& Freeman, 2015; Vanderveldt et. al., 2016).

Os estudos envolvendo situações de escolhas alomórficas foram realizados com macacos rhesus (Huskinson et al., 2016); Huskinson et al., 2015) e com seres humanos 
(e.g., Bickel et al., 2011; Mitchell et al., 2004; Yoon, Higgins, Bradstreet, Badger, \& Thomas, 2009). Todos eles apresentaram como uma das alternativas alguma droga (cocaína ou nicotina, por exemplo) em concorrência com algum reforçador que não fosse uma droga (como pelotas de comida ou quantias de dinheiro). De modo geral, essas pesquisas partiam da definição de "abuso de drogas" como escolha recorrente do uso de drogas quando reforçadores de outra natureza estão disponíveis, portanto, seu objetivo era avaliar o efeito do atraso na escolha pela droga quando havia um reforçador de outra natureza sendo oferecido como opção (Huskinson et al., 2016; Huskinson et. al., 2015).

No estudo de Huskinson et al. (2015), os autores avaliaram o grau de desvalorização em condições isomórficas e alomórficas, utilizando oito macacos rhesus machos. Na condição isomórfica, o reforçador utilizado em ambas as alternativas eram pelotas de comida, sendo que, na alternativa imediata, o número de pelotas variou sistematicamente entre 1 e 8 pelotas, enquanto que a alternativa com atraso, o número de pelotas permaneceu fixo em 4. Cada sessão consistiu em quatro tentativas forçadas (duas para cada alternativa) e dezesseis alternativas de escolha livre. Em cada alternativa estava em vigor um esquema de FR 5. Os sujeitos passaram por quatro atrasos, que variaram entre 0 e 120s. Tanto os atrasos quanto as quantidades de pelotas foram apresentadas de forma não descendente nem ascendente. Os autores verificaram que, conforme a magnitude da alternativa imediata aumentou, a escolha por essa alternativa diminuiu. Além disso, os autores obtiveram os valores de $k$, utilizando a Equação 2 (com o valor de $s$ igualado a 1). O procedimento da situação alomórfica foi similar à da situação isomórfica, com a diferença que o reforçador apresentado na alternativa imediata foi uma injeção de cocaína de 10 segundos de duração, cuja concentração variou entre 0,003 e $0,4 \mathrm{mg} / \mathrm{kg} /$ injeção. Para alguns animais, foram disponibilizadas, na alternativa com atraso, 4 pelotas de comida e, para outros, 8 pelotas. Isso foi feito para avaliar se haveria diferenças no grau 
de desvalorização para magnitudes diferentes do reforçador apresentado com atraso ${ }^{1}$. Também na situação alomórfica verificou-se que a escolha pelo reforçador imediato diminuiu conforme a concentração de cocaína diminuiu. Os autores obtiveram os valores de $k$ também para a situação alomórfica. Comparando os valores de $k$ para as situações isomórficas e alomórficas, os autores verificaram que a desvalorização foi maior na condição isomórfica.

Para discutir esse dado, os autores levantaram duas hipóteses (Huskinson et al., 2015). A primeira é a de que, quando os reforçadores apresentados nas duas alternativas são completamente substituíveis (conferir adiante a discussão sobre a relação econômica entre reforçadores), a desvalorização é menor do que quando os reforçadores são só parcialmente substituíveis. Contudo, os autores afirmam que não há estudos sistemáticos sobre o efeito do grau de substitutabilidade na desvalorização pelo atraso e sugerem que se realizem estudos para investigar a relação entre esses fenômenos. A outra hipótese levantada é a de que essa diferença no grau de desvalorização se deveria ao fato de que a cocaína tem como um de seus efeitos inibir o apetite, diminuindo a proporção de escolha por comida. Além disso, os autores verificaram que os dados foram bem descritos pela Equação 2 (com o valor de $s$ igual a 1), cuja curva é uma hipérbole. Os autores afirmam que, considerando essa diferença nos graus de desvalorização das condições isomórfica e alomórfica, pesquisas futuras precisarão investigar, em condição alomórfica, o efeito de variáveis estudadas somente em condições isomórficas.

Considerando que, no estudo de Huskinson et al. (2015) a condição alomórfica consistiu somente em apresentar cocaína sem atraso e comida com atraso, Huskinson et al. (2016) investigou uma condição de escolha em que foi apresentada comida sem atraso

\footnotetext{
${ }^{1} \mathrm{O}$ nome do fenômeno observado em experimentos com humanos em que há diferença no grau de desvalorização quando se modifica a magnitude do valor reforçador apresentado com atraso é efeito de magnitude. Para uma revisão das discussões sobre se há ou não efeito de magnitude em animais não humanos, conferir (Green, Myerson, \& Vanderveldt, 2014)
} 
e cocaína com atraso. O procedimento utilizado foi similar ao de Huskinson et al. (2016). O número de pelotas de comida variou sistematicamente entre 1 a 16 . Os atrasos com que as pelotas de alimento foram apresentadas variou entre 0 e 720 s. Foram obtidos graus de desvalorização para duas doses de cocaína: 0,1 ou $0,2 \mathrm{mg} / \mathrm{kg} /$ injeção. Os autores verificaram, conforme a literatura, que, conforme o atraso para disponibilização da cocaína aumentou, a proporção de escolha por ela diminuiu. Quando os valores de $k$ obtidos foram comparados com os da situação alomórfica do estudo de Huskinson et al. (2015), verificou-se que a desvalorização foi maior quando o reforçador apresentado sem atraso foi a comida. Os autores sugerem que, considerando os dados obtidos, o grau de desvalorização pode variar não só entre situações isomórficas e alomórficas, mas também, em situações alomórficas, dependendo de quais estímulos são apresentados com e sem atraso. Isso faz com que seja necessário investigar o efeito de manipulações experimentais não só em uma dessas condições, mas em todas.

\section{Privação e desvalorização pelo atraso}

O estudo do efeito da privação sobre a desvalorização pelo atraso tem apresentado resultados conflitantes e uma das possíveis variáveis relevantes para compreensão desses resultados é a diferença entre o efeito da privação em situações isomórficas e alomórficas (Belke \& Kwan, 2000; Bradshaw \& Szabadi, 1992; Christensen-Szalanski, Goldberg, Anderson, \& Mitchell, 1980; Ho, Wogar, Bradshaw, \& Szabadi, 1997; Logue, Chavarro, Rachlin, \& Reeder, 1988; Logue \& Peña-Correal, 1985; Oliveira, Calvert, Green, \& Myerson, 2013; Richards et al., 1997; Wogar, Bradshaw, \& Szabadi, 1992). Em um estudo cujo objetivo era investigar os efeitos do aumento dos níveis de privação atuais e passados na desvalorização pelo atraso (Christensen-Szalanski et al., 1980), 32 ratas Long-Evans fêmeas tiveram acesso livre a água e alimento até os seis meses de idade, sendo, então, divididas em dois grupos. Os membros de um dos grupos (G1) passaram a 
ter o acesso à água restrito a $10 \mathrm{~g}$ diárias, até que seus pesos ficassem em torno de $70 \%$ do peso ad-lib; o outro grupo $(\mathrm{G} 2)^{2}$ continuou tendo acesso livre a água e alimento. Após dois meses, o grupo com acesso restrito à água voltou para o regime ad-lib e permaneceu nele até que o peso dos animais estabilizasse. Aos nove meses de idade, os animais tiveram o acesso à água restrito até que atingissem $90 \%$ do peso ad-lib e passaram por um treino de pressão à barra em uma caixa de condicionamento operante equipada com duas barras. Então, os dois grupos (G1 e G2) foram, cada um, divididos em dois, sendo que um dos subgrupos teve acesso restrito à água até que atingisse $70 \%$ do peso ad-lib (G1A e G2A) e o outro subgrupo teve acesso restrito à água até atingir 95\% do peso adlib (G1B e G2B). Nessa condição de peso, os animais passaram por uma tarefa de desvalorização pelo atraso em que a pressão de uma das barras da caixa operante era seguida de um timeout de 10 s, após o qual ocorria liberação de $0,25 \mathrm{~g}$ de água. A pressão da outra barra produzia um timeout cuja duração $(\mathrm{X})$ variou de acordo com a condição experimental $(0 ; 2,5 \mathrm{~s} ; 5 \mathrm{~s} ; 7 \mathrm{~s})$; depois desse timeout, eram liberados $0,05 \mathrm{~g}$ de água, que eram seguidos de outro timeout cuja duração era calculada subtraindo a quantidade $\mathrm{X}$ de 10s (de modo a igualar a duração das tentativas com maior e menor atraso para apresentação dos reforçadores). Cada uma das durações de atraso permaneceu em vigor por cinco sessões.

Os resultados obtidos por Christensen-Szalanski et al. (1980) mostraram que houve aumento da preferência pela alternativa com maior atraso e magnitude conforme o atraso para o reforçador de menor magnitude aumentou. Além disso, os animais com níveis altos de privação tanto prévios quanto ao longo da realização da tarefa de desvalorização pelo atraso mostraram maior preferência pela alternativa com maior magnitude e atraso. Para

\footnotetext{
${ }^{2}$ As siglas apresentadas foram utilizadas para facilitar a identificação dos grupos, mas não constam do estudo original de Christensen-Szalanski (1980).
} 
discutir esse resultado, os autores levantaram a hipótese de que os animais adotam duas estratégias distintas para obtenção de recursos. Em condição de escassez de recurso, os animais adotam o que os autores chamaram de estratégia de "curto prazo", que maximizaria a obtenção de recurso. Quando o recurso fosse abundante, os animais adotariam estratégias de "longo prazo", abrindo mão da maximização em favor da obtenção de recursos mais variados.

A fim de investigar diferentes regimes de privação atuais na desvalorização pelo atraso, Logue e Pena-Correal (1985) realizaram um estudo com dois experimentos. No Experimento 1, quatro pombos White-Carneaux machos e adultos passaram incialmente por um procedimento de autoshaping para aprender a bicar as chaves iluminadas presentes na caixa de condicionamento operante. Depois disso, passaram por uma tarefa de desvalorização pelo atraso em que a bicada em uma das chaves produzia $6 \mathrm{~s}$ de acesso a alimento após um intervalo de $6 \mathrm{~s}$; a bicada na outra chave produzia acesso de $2 \mathrm{~s}$ a alimento após um intervalo cuja duração variava de acordo com a condição $(1 \mathrm{~s} ; 2 \mathrm{~s} ; 3 \mathrm{~s}$; 4s; 6s). Cada duração de atraso para o reforçador de menor magnitude ficou em vigor por no mínimo 10 sessões e até a média de escolha do reforçador de maior magnitude nas últimas cinco sessões diferir em, no máximo, quatro da média de escolha pelo mesmo reforçador nas cinco sessões anteriores. Os animais passaram por cada atraso em três condições de privação diferentes: $65 \%, 80 \%$ e $95 \%$ do peso ad-lib, sendo que o peso era controlado por meio da variação da quantidade de alimento disponibilizado após a sessão experimental. Os resultados obtidos mostraram que a escolha pela alternativa de maior atraso e magnitude aumentou conforme o atraso para a alternativa com menor magnitude aumentou. Por outro lado, não houve diferença estatisticamente significativa na escolha pela alternativa de maior magnitude nas diferentes condições de privação. 
No Experimento 2 (Logue \& Pena-Correal, 1985), quatro pombos White Carneaux machos e adultos não ingênuos realizaram uma tarefa de desvalorização pelo atraso similar ao do Experimento 1. No entanto, os regimes de privação aos quais foram expostos foram diferentes. Na primeira condição de privação, os animais realizaram a tarefa de desvalorização com $80 \%$ do peso ad-lib, com o peso controlado por meio do fornecimento de comida após a sessão experimental. Na segunda condição, os animais realizaram a tarefa de desvalorização, mas agora não recebiam comida após as sessões, ficando com, aproximadamente, $65 \%$ do peso ad-lib. A terceira condição de privação foi exatamente igual a primeira. Assim como no Experimento 1, o aumento no atraso diminuiu a escolha pela alternativa de menor magnitude, sem que as diferentes condições de privação afetação de forma significativa essa desvalorização. Os autores não apresentam hipóteses a respeito da diferença de resultados em relação ao experimento de Christensen-Szalanski et al. (1980), mas sugerem que pesquisas futuras usem procedimentos mais parecidos com as condições dos ambientes naturais das espécies.

Logue et al. (1988) utilizaram o mesmo procedimento e quatro sujeitos de Logue e Pena-Correal (1985) para comparar a proporção de escolhas da alternativa imediata em quatro condições diferentes. Na Condição 1, os animais passaram por 15 sessões de 23 horas (que ocorriam a cada quatro dias) e eram mantidos a $80 \%$ do peso ad-lib; a Condição 2, era igual à Condição 1, com a diferença de que os animais tinham acesso livre ao alimento na caixa viveiro; a Condição 3 foi igual à Condição 2, com a diferença de que agora as 15 sessões ocorreram em dias seguidos; na Condição 4, a duração total de cada tentativa foi diminuído de forma a fazer com que, caso os animais demorassem a escolher a alternativa sem atraso, havia chance de a tentativa acabar antes do reforçador ser liberado. Os resultados encontrados não mostraram nenhuma diferença significativa entre as condições. Para discutir essa ausência de efeito da privação na desvalorização, os 
autores levantam a hipótese de que as condições experimentais do estudo podem não trazer muita informação sobre o modo como os animais fazem escolhas em ambiente natural, uma vez que utilizou reforçadores iguais nas duas alternativas e a exigência para conseguir cada reforçador (por exemplo, número de respostas) era igual. Essas condições seriam incomuns e, dessa forma, seria necessário realizar experimentos cujo delineamento se assemelhasse às condições do ambiente natural dos animais, sugestão que corrobora a afirmação de Huskinson et al. (2015) sobre a necessidade de realizar tarefas de desvalorização em condição alomórfica.

Bradshaw e Szabadi (1992) procuraram investigar o efeito da privação na desvalorização pelo atraso, partindo da discussão do modelo matemático proposto por Herrnstein (1981), cuja equação para identificar a duração do atraso no ponto de indiferença entre as duas alternativas (em situações com tentativas discretas) seria:

$$
\Delta^{\prime}=K_{H}(\mathrm{a}-1) / \mathrm{I}
$$

$\mathrm{Na}$ Equação 3, $\Delta^{\prime}$ é o atraso no ponto de indiferença, $a$ é uma constante calculada pela razão $\left(\mathrm{Q}_{\mathrm{B}} / \mathrm{Q}_{\mathrm{A}}\right)$, sendo que $\mathrm{Q}_{\mathrm{B}}$ é a magnitude do reforçador apresentado com atraso e $\mathrm{Q}_{\mathrm{A}}$, a magnitude do reforçador apresentado sem atraso e, nos casos em que esse modelo seria válido, $\mathrm{Q}_{\mathrm{B}}>\mathrm{Q}_{\mathrm{A}}$. A equação apresenta dois parâmetros livres: $K_{H}$, que é a frequência de apresentação do reforçador necessária para manter a frequência de respostas na metade da frequência máxima teoricamente possível e $I$, que é uma constante que modula o efeito do atraso. Bradshaw e Szabadi (1992) afirmam que as pesquisas empíricas com tentativas discretas publicadas até então sugeriam que o parâmetro $K_{H}$ variaria de forma inversamente proporcional ao nível de privação. Sendo assim, aumentar o nível de privação faria com que o valor de $K_{H}$ diminuísse, assim como o valor de $\Delta^{\prime}$. Na prática, isso faria com que os sujeitos aumentassem a proporção de escolha do reforçador menor 
e imediato. Para testar essa hipótese, os autores, no Experimento 3 de seu estudo, apresentaram a oito ratos Wistar machos ingênuos uma tarefa de desvalorização pelo atraso em que a pressão de uma das barras, em uma caixa de condicionamento operante, produzia acesso imediato a $0,05 \mathrm{ml}$ de uma solução de sacarose com concentração de 0,05M; a pressão na outra barra produzia acesso a $0,05 \mathrm{ml}$ de solução de sacarose com concentração de $0,32 \mathrm{M}$ após um atraso cuja duração variou entre seis diferentes condições $(0 \mathrm{~s} ; 2 \mathrm{~s} ; 4 \mathrm{~s} ; 8 \mathrm{~s} ; 16 \mathrm{~s} ; 32 \mathrm{~s})$. Cada atraso permaneceu em vigor por, no mínimo, 21 sessões e até que a inspeção visual dos dados deixasse de mostrar tendências ascendentes ou descendentes. O experimento teve duas fases, sendo que, na Fase I, os animais foram divididos em dois grupos. No Grupo 1 (conforme nomeação dos autores), quatro ratos foram mantidos a $80 \%$ do peso ad-lib e no Grupo 2, outros quatro ratos foram mantidos a $90 \%$ do peso ad-lib. Na Fase II, os animais continuaram divididos nos mesmos grupos, mas o peso de cada grupo foi invertido. A tarefa de desvalorização descrita foi apresentada aos animais na Fase I e reapresentada na Fase II, de modo a fazer com que fossem expostos a cada um dos seis atrasos duas vezes, com pesos diferentes em cada uma delas. Os resultados obtidos mostraram que houve diminuição na escolha pelo reforçador de maior magnitude conforme o atraso para sua apresentação aumentou. Além disso, também mostraram que essa diminuição foi menos intensa quando os animais estavam com $90 \%$ do peso ad-lib, comparada à quando estavam com $80 \%$ do peso. $\mathrm{Ou}$ seja, quando o nível de privação estava mais intenso, os animais tenderam a manter a preferência pela alternativa atrasada e de maior magnitude.

Os resultados de Bradshaw e Szabadi (1992) corroboram os apresentados por Christensen-Szalanski et al. (1980), mas não os encontrados por Logue e Pena-Correal (1985) e Logue et al. (1988). Além disso, os resultados de Bradshaw e Szabadi (1992) contrariam a hipótese levantada pelos próprios autores (a partir da discussão dos modelos 
matemáticos) de que o aumento da privação faria com que os animais escolhessem mais a alternativa de menor magnitude e atraso. Para explicar essa diferença nos resultados, Bradshaw e Szabadi (1992) propõem interpretar os dados a partir de um modelo matemático que une dois outros modelos. O primeiro é uma variação do apresentado por Herrnstein (1981) e descreve o valor de um estímulo reforçador apresentado sem atraso:

$$
\mathrm{V}_{\mathrm{i}}=\left(\mathrm{V}_{\max } \cdot \mathrm{q}\right) /\left(\mathrm{Q}^{\prime}+\mathrm{q}\right)
$$

Na Equação 4, $V_{i}$ é o valor reforçador do estímulo apresentado sem atraso; $V_{\max }$, o valor teórico máximo que o estímulo pode ter; $q$, a magnitude absoluta do estímulo; $Q$ ', a magnitude necessária para que o estímulo tenha metade do valor teórico máximo. De acordo com os autores, as evidências empíricas publicadas até então, indicariam que $Q^{\prime}$ varia de forma inversamente proporcional ao nível de privação (assim como a variável $K_{h}$ na Equação 3); então, no caso do experimento realizado, $Q^{\prime}{ }_{80}<Q_{90}^{\prime}$, em que os valores subscritos representam a porcentagem do peso ad-lib. O segundo modelo a ser integrado ao primeiro é o modelo hiperbólico de desvalorização apresentado por Mazur (1987), descrito na Equação 1. Fazendo as adaptações necessárias para integração dos modelos, os autores (Bradshaw \& Szabadi, 1992) apresentam o modelo hiperbólico da seguinte forma:

$$
\mathrm{V}_{\mathrm{d}}=\mathrm{V}_{\mathrm{i}} /(1+\mathrm{kD})
$$

$\mathrm{Na}$ Equação $5, V_{d}$ é o valor do estímulo apresentado com atraso e $V_{i}$, o valor do estímulo apresentado sem atraso, como na Equação 4. De acordo com os autores (Bradshaw \& Szabadi, 1992), quando se descreve o atraso no ponto de indiferença entre duas alternativas $\left(d^{\prime}{ }_{B}\right)$ a partir das Equações 4 e 5, identificam-se duas variáveis que poderiam influenciar a desvalorização pelo atraso: 


$$
\mathrm{d}_{\mathrm{B}}^{\prime}=(1 / \mathrm{k}) \cdot\left[\left(\mathrm{aQ} \mathrm{Q}^{\prime}+\mathrm{aq}_{\mathrm{A}}\right) /\left(\mathrm{Q}^{\prime}+\mathrm{aq}_{\mathrm{A}}\right)-1\right]
$$

$\mathrm{Na}$ Equação 6, $q_{A}$ é a magnitude do reforçador apresentado sem atraso. De acordo com essa Equação, a desvalorização pelo atraso dependeria (além de $Q^{\prime}$ ) de $k$ (como já sugere Mazur (1987)) e da magnitude do reforçador apresentado sem atraso. Os autores levantam a hipótese de que, assim como ocorre com $Q$ ', o valor de $k$ também variaria de acordo com o nível de privação. Seriam necessárias, no entanto, pesquisas empíricas para investigar se isso ocorre e se o valor de $k$ é direta ou inversamente proporcional ao nível de privação (por exemplo, $k_{80}>k_{90}$ ou $k_{80}<k_{90}$, em que os valores subscritos representam a porcentagem do peso ad-lib). Então, o fato de os resultados obtidos contrariarem a hipótese original do artigo e os dados de Logue e Pena-Correal (1985) e Logue et al. (1988) poderia ser devido às diferentes magnitudes do estímulo apresentado sem atraso ou do efeito do tipo de relação entre $k$ e os níveis de privação.

Para testar a hipótese de que a magnitude absoluta dos estímulos reforçadores influencia o efeito da privação na desvalorização pelo atraso (Bradshaw \& Szabadi, 1992), Wogar et al. (1992) realizaram um estudo com uma tarefa de desvalorização pelo atraso diferente. Eles destacam o fato de que os estudos sobre o efeito da privação na desvalorização realizados até então (Christensen-Szalanski et al., 1980; Logue \& PenaCorreal, 1985; Logue et al., 1988; Bradshaw \& Szabadi, 1992) utilizaram um procedimento que os autores denominaram como "sistemático", ou seja, os atrasos na apresentação do estímulo de maior magnitude são mantidos ao longo de várias sessões, variando de acordo com certos critérios de estabilidade. Os pontos de indiferença, nesses casos, são estimados a partir da condição de atraso em que há reversão na preferência entre os estímulos com maior e menor atraso. De acordo com os autores, uma forma mais

\footnotetext{
${ }^{3}$ É possível consultar a derivação da Equação 6 a partir das Equações 4 e 5 no artigo original de Bradshaw e Szabadi (1992)
} 
precisa de obter os pontos de indiferença seria a utilização dos procedimentos de ajuste ${ }^{4}$, como o de Mazur (1987), apresentado anteriormente.

No Experimento 1, Wogar et al. (1992) 16 ratas Wistar fêmeas realizaram uma tarefa de desvalorização pelo atraso que consistia em 10 blocos com quatro tentativas de 45s de duração. Duas tentativas eram forçadas (só havia uma alternativa disponível) e outras duas eram livres (o animal podia escolher entre duas alternativas). Se o animal pressionasse uma das barras (Barra A), uma pelota de comida era liberada após um intervalo de 2s; se pressionasse a outra barra (Barra B), eram liberadas duas pelotas de comida após um atraso variável $\left(d_{B}\right)$. Caso a Barra A fosse escolhida duas vezes seguidas nas tentativas livres, a duração de $d_{B}$ diminuía em $30 \%$ no próximo bloco; caso a Barra $\mathrm{B}$ fosse escolhida duas vezes seguidas nas tentativas livres, a duração de $d_{B}$ aumentava em $30 \%$ no próximo bloco. O Experimento 1 foi dividido em duas fases, cada uma com 60 sessões. Na Fase I, metade dos animais foi mantida a $80 \%$ do peso ad-lib e a outra metade, a $90 \%$. Na Fase II, os pesos foram invertidos. Os resultados obtidos mostraram que o valor de $d_{B}$ no ponto de indiferença $\left(d^{\prime}{ }_{B}\right)$ foi estatisticamente significativo quando os animais estavam com $80 \%$ do peso comparado a quando estavam com $90 \%$. Os autores argumentam que, além de indicar que o efeito da privação na desvalorização também ocorre em procedimentos de ajuste, os resultados obtidos sugerem que o aumento da privação diminui o valor de $k$ (na Equação 6), fazendo com que $k_{80}<k_{90}$. De acordo com os autores, essa possível diminuição em $k$, poderia explicar a diferença dos resultados de Bradshaw e Szabadi (1992) em relação às previsões de Herrnstein (1981). Isso porque a relação $k_{80}<k_{90}$ anularia os efeitos da relação $Q{ }^{\prime}{ }_{80}<Q{ }^{\prime}{ }_{90}$ (Equação 4), a qual, caso não houvesse alteração em $k$, faria com que, em níveis mais severos de privação, os animais

\footnotetext{
${ }^{4}$ Consultar o estudo de Peterson, Hill e Kirkpatrick (2015) (discutido na seção “Método” desse estudo) para uma comparação empírica das diferenças entre procedimentos sistemáticos e de ajuste.
} 
preferissem a alternativa de menor magnitude e menor atraso (oposto do que é sugerido pelos resultados apresentados). Contudo, os autores sugerem que seriam necessárias pesquisas empíricas para avaliar se, de fato, há alteração no valor de $k$.

No Experimento 2 (Wogar et al., 1992), os autores procuraram avaliar a hipótese de que a magnitude absoluta dos reforçadores alteraria o efeito da privação na desvalorização pelo atraso (como sugerido por Bradshaw e Szabadi (1992)). Para isso, apresentaram a mesma tarefa de desvalorização por ajuste do atraso do Experimento 1 a 20 ratas Wistar fêmeas. Nesse experimento, os animais foram divididos em quatro grupos, que realizaram a tarefa de ajuste em quatro condições, apresentadas em ordens diferentes para cada grupo: (1) 80\% do peso ad-lib; Barra A (sem atraso) dando acesso a uma pelota de comida e Barra B (com atraso), dando acesso a duas pelotas; (2) 80\% do peso ad-lib; Barra A liberando três pelotas e Barra B, seis pelotas; (3) 90\% do peso ad-lib; Barra A liberando uma pelota e Barra B, duas pelotas; (4) 90\% do peso ad-lib; Barra A liberando três pelotas e Barra $\mathrm{B}$, seis pelotas. Os resultados obtidos mostraram que, quando a razão entre pelotas distribuídas foi 1:2, o $d^{\prime}{ }_{B}$ foi maior quando peso era $80 \%$ ad-lib (replicando o Experimento 1 (Wogar et al., 1992)). Contudo, quando a razão entre pelotas foi de 3:6, não houve diferença significativa entre os valores de $d^{\prime}{ }_{B}$ obtidos nas duas condições de privação.

De acordo com Wogar et al. (1992), os dados dos Experimentos 1 e 2 mostram que tanto a privação quanto a magnitude absoluta dos reforçadores alteram a desvalorização pelo atraso, ainda que de formas opostas. Além disso, argumentam que os dados corroboram as relações $k_{80}<k_{90}$ e $Q{ }^{\prime}{ }_{80}<Q{ }^{\prime}{ }_{90}$. Dessa forma, os dados apresentados dariam suporte ao modelo proposto por Bradshaw e Szabadi (1992) e à explicação feita a partir dele de que as diferenças nos dados sobre o efeito da privação na desvalorização 
podem se dever ao fato de que esse efeito depende da ação de diversas variáveis, como $q_{A}$ e $a$ (Equação 6).

Ainda discutindo as implicações do modelo de Bradshaw e Szabadi (1992), Ho et al. (1997) sugerem que a análise da condição de indiferença revelaria ainda uma outra variável relevante no estudo da privação e da desvalorização:

$$
\mathrm{V}_{\mathrm{d}(\mathrm{A})}=\mathrm{V}_{\mathrm{d}(\mathrm{B})}
$$

Em que $d(A)$ representa a alternativa de menor magnitude e $d(B)$, a alternativa de maior magnitude. Outra forma de descrever o atraso para a alternativa de maior magnitude no ponto de indiferença $\left(d^{\prime}{ }_{B}\right)$, partindo das Equações 4 e 5 seria:

$$
\mathrm{d}_{\mathrm{B}}=(1 / \mathrm{k}) \cdot\left(\mathrm{V}_{\mathrm{i}(\mathrm{B})}-\mathrm{V}_{\mathrm{i}(\mathrm{A})} / \mathrm{V}_{\mathrm{i}(\mathrm{A})}\right)+\mathrm{d}_{\mathrm{A}} \cdot\left(\mathrm{V}_{\mathrm{i}(\mathrm{B})} / \mathrm{V}_{\mathrm{i}(\mathrm{A})}\right)
$$

Nessa Equação, $V_{i(A)}$ e $V_{i(B)}$ são os valores dos reforçadores de menor e maior magnitude, respectivamente, como calculados a partir da Equação 4; $\mathrm{d}_{\mathrm{A}}$ é o atraso para o reforçador com menor magnitude; $k$ é o parâmetro livre da Equação 5. Sendo assim, de acordo com os autores, $d_{B}^{\prime}$ dependeria também de $d_{A}$ que seria, então, uma variável importante no estudo do efeito da privação na desvalorização. Para testar essa hipótese, 20 ratas Wistar fêmeas foram divididas em dois grupos de 10 animais, em que um era mantido a $80 \%$ do peso ad-lib e outro, a 90\%. Os animais realizaram a mesma tarefa de desvalorização por ajuste do atraso de Wogar et al. (1992, Experimento 1), com a diferença que a escolha pela Barra A (menor atraso) duas vezes seguidas em tentativas livres fazia com que o atraso para o reforçador da Barra B $\left(d_{B}\right)$ diminuísse em $20 \%$ no próximo bloco e, inversamente, se a Barra B fosse escolhida em duas vezes seguidas em tentativas livres, $d_{B}$ aumentaria em $20 \%$ no próximo bloco. O experimento teve quatro fases, nas quais os animais realizaram a tarefa de desvalorização por ajuste em condições diferentes. Na Fase I (com 60 sessões), o reforçador da Barra A foi apresentado com um atraso de $2 \mathrm{~s}\left(d_{A}=\right.$ 
2s). Nas fases II e III (com 40 sessões cada), $d_{A}$ aumentou para $4 \mathrm{~s}$ e 8 s respectivamente. Na Fase IV (com 40 sessões), $d_{A}$ voltou a 2 s. Os resultados obtidos mostraram que, nas Fases I e IV, em que $d_{A}$ valia 2 s, o valor de $d_{B}$ foi mais alto para o grupo mantido a $80 \%$ do peso do que para o grupo mantido a 90\% (replicando os dados de Wogar et al. (1992, Experimento 1)). Porém, nas Fases II e III, essa diferença não foi estatisticamente significativa (replicando os dados de Wogar et al. (1992, Experimento 2)). Dessa forma, os autores argumentaram que o efeito da privação na desvalorização pelo atraso depende não só da magnitude absoluta dos estímulos (Wogar et al., 1992) como de $d_{A}$. Assim, a privação poderia aumentar, diminuir ou não mudar os valores de $d_{B}$, dependendo da magnitude e do atraso utilizados.

No estudo de Richards et al. (1997) citado acima, foram comparados os valores estimados de $k$ (Equação 1) para um grupo com acesso a 20 minutos de água após as sessões experimentais e para um grupo com 4 horas de acesso a água após as sessões experimentais. Para isso, oito ratos Sprague-Dawley machos passaram pela tarefa de desvalorização descrita acima duas vezes, uma para cada condição de privação. Assim como em Logue e Pena-Correal (1985) e Logue et al. (1988), também não foram encontradas diferenças no grau de desvalorização entre as condições com e sem privação. Como possível explicação para a ausência de efeitos da privação, os autores retomam a hipótese de Logue et al. (1988) de que quando se usa o mesmo estímulo reforçador nas duas alternativas, a variação dos níveis de privação altera os valores absolutos de cada alternativa, mas não seu valor relativo, fazendo com que a preferência por cada um deles não mude. Contudo, os autores não discutem as hipóteses levantadas por Bradshaw e Szabadi (1992), Wogar et al. (1992) e Ho et al. (1997) a respeito da influência das magnitudes e dos atrasos absolutos de cada alternativa no efeito da privação sobre a desvalorização. Além disso, os dados de Richards et al. (1997) contrariam a hipótese de 
Wogar et al. (1992) e Ho et al. (1997) de que diferentes condições de privação mudam o valor de $k$ (Equação 5). Porém, é importante ressaltar, que o regime de privação de Richards et al. (1997) (alteração da diferença entre o horário da sessão e o da liberação da última refeição) e o dos estudos anteriores (alteração do peso corporal) foram diferentes, o que pode ter influenciado os resultados.

A fim de verificar se a privação altera o padrão de escolha entre alimentos preferidos e não preferidos apresentados com atraso, Belke e Kwan (2000) utilizaram um procedimento de ajuste do atraso similar ao de Mazur (1987). Os autores aplicaram um critério de inclusão a um grupo de pombos que consistiu em avaliar quais animais, com acesso livre a ração e milho nas gaiolas, consumiam mais milho do que ração em 10 dias seguidos. Com base nisso, seis pombos foram escolhidos e divididos em grupos iguais, sendo que cada grupo foi exposto a diferentes condições de privação para variar o peso corporal. Os animais do Grupo 1 foram mantidos a 70\%, 95\% e 70\% do peso ad-lib. Os animais do Grupo 2, a 95\%, 70\% e 95\% do peso ad-lib. Em cada condição, os animais realizaram uma tarefa de desvalorização em que 64 tentativas eram divididas em blocos de quatro tentativas, das quais duas eram livres e duas forçadas. Nas tentativas livres, bicar uma das chaves tinha como consequência um atraso de $5 \mathrm{~s}$ após o qual era liberado o acesso ao funil contendo ração por 3s; se a outra chave fosse bicada, eram liberados $3 \mathrm{~s}$ de acesso ao funil de milho após um atraso variável. Caso a ração fosse escolhida em duas tentativas livres seguidas no mesmo bloco, o atraso para a liberação do milho diminuía em 1s no bloco seguinte; caso o milho fosse escolhido em duas tentativas livres seguidas no mesmo bloco, o atraso para sua liberação aumentava em 1s no próximo bloco. $\mathrm{O}$ atraso para apresentação do milho foi variado até que se encontrasse o ponto de indiferença. Essa tarefa foi repetida pelos dois grupos em cada uma das condições de privação. Os resultados obtidos mostraram que os atrasos na indiferença foram maiores quando os 
animais estavam com $95 \%$ do peso ad-lib. Esses resultados são opostos aos de Christensen-Szalanski et al. (1980), Bradshaw e Szabadi (1992), Wogar et al. (1992), Ho et al. (1997). Apesar dos autores não discutirem essa diferença, é possível levantar a hipótese de que o tipo de reforçador utilizado em cada alternativa também influencie o efeito da privação na desvalorização, hipótese que vai ao encontro da levantada por Logue et al. (1988) e das propostas de Huskinson et al. (2015). Também, com base nas hipóteses de Wogar et al. (1992) e Ho et al. (1997), pode-se sugerir que a mudança no tempo de acesso para cada funil e no atraso para a liberação da ração alteraria a preferência dos animais.

Em um estudo mais recente, Oliveira et. al. (2013) realizaram dois experimentos cujo objetivo era investigar o efeito de duas condições diferentes de privação de alimento no valor estimado de $k$, utilizando pombos em uma tarefa de ajuste de quantidade similar à de Richards et al. (1997). As duas condições de privação foram: (1) alteração de peso e (2) sessões experimentais que ocorriam com animais privados de comida por 23 horas. No Experimento 1, cinco pombos foram expostos a um delineamento ABA, em que as fases A consistiam em realizar uma tarefa de desvalorização pelo atraso com peso entre $90 \%$ e $95 \%$ do peso ad-lib e as fases B, em realizar a mesma tarefa com peso entre $70 \%$ e $80 \%$ do peso ad-lib. A tarefa consistiu em um procedimento de ajuste de quantidade entre sessões, no qual a quantidade de pelotas de alimento da alternativa imediata era variada entre as sessões de acordo com a escolha dos sujeitos: se os animais escolhessem a alternativa imediata em mais do que $60 \%$ em três sessões seguidas, a quantidade de pelotas era diminuída na próxima sessão; se essa alternativa fosse escolhida em menos de $40 \%$ das vezes em três sessões seguidas, a quantidade de pelotas era aumentada na sessão seguinte. $\mathrm{O}$ critério para se considerar que se alcançou o ponto de indiferença era que a alternativa imediata fosse escolhida entre $40 \%$ e $60 \%$ das vezes. A partir dos pontos de 
indiferença obtidos, estimou-se o valor de $k$ para cada uma das condições de privação. Os resultados indicaram que a manipulação da privação não alterou os valores de estimados de $k$. O Experimento 2 consistiu em expor seis pombos ao mesmo procedimento de ajuste de quantidade, mas agora eles eram mantidos entre $80 \%$ e $85 \%$ do peso ad-lib e expostos a dois tipos de sessões experimentais, um em que estavam a 1 hora sem alimentação antes da sessão e outro em que estavam a 23 horas sem alimentação antes da sessão. Obteve-se os pontos de indiferença para cada uma das condições e, a partir dele, os valores estimados de $k$. Nesse experimento, como no anterior, não se verificou diferenças significativas entre os valores de $k$ para cada uma das condições.

Os dados de Oliveira et. al. (2013) indicam que, mesmo com a distinção entre os dois tipos de regime, a privação não alterou a desvalorização pelo atraso. De acordo com os autores, seus resultados estão de acordo com a proposta de (Herrnstein, 1970) de que o que determina a escolha é o valor reforçador relativo dos estímulos. Ou seja, uma alternativa é escolhida com base na comparação de suas propriedades com as da outra alternativa e não com base nos valores absolutos dessas propriedades. Sendo assim, nos procedimentos de escolha isomórfica, a privação produz alterações equivalentes nas propriedades de cada alternativa (verificadas pelo mesmo valor de $k$ nas duas condições), já que a privação aumenta o valor reforçador de ambas. Em situações de escolha alomórfica a privação teria um efeito mais significativo nas propriedades de apenas um dos reforçadores, o que faria com que houvesse diferença entre as condições com e sem privação no que diz respeito ao valor reforçador relativo das alternativas, tendo como efeito padrões de escolha diferentes entre as duas condições. Novamente, essa hipótese é similar à de Logue et al. (1988) e às propostas de Huskinson et al. (2015).

\section{Correr na roda de atividades e consumo de solução de sacarose}


Uma possibilidade de estímulo reforçador a ser apresentado de forma concorrente à solução de sacarose é o correr na roda de atividades, uma vez que a relação entre correr na roda, privação de alimento e consumo de água açucarada tem sido sistematicamente analisada. Partindo dos dados de Belke (2004), os quais mostraram que alterar o nível de privação por meio da mudança corporal aumentou o consumo tanto de solução de sacarose quanto do correr na roda em esquemas múltiplos nos quais cada componente tinha como reforçador um dos estímulos, Belke, Duncan e Pierce (2006) argumentam que, a fim de entender quadros como a anorexia nervosa - em que a atividade física e o consumo de alimento assumem uma relação disfuncional para o indivíduo - seria necessário avaliar o consumo desses reforçadores em situação concorrente, investigando em quais condições cada um dos reforçadores é escolhido com maior frequência. Os autores retomam o conceito de substitutabilidade da economia comportamental para descrever as possíveis relações entre os dois estímulos.

De acordo com Green e Freed (1993), a substitutabilidade é um continuo que procura descrever a relação entre custo e consumo de dois ou mais reforçadores. Em um extremo do contínuo estão os reforçadores perfeitamente substitutos; nesse caso, quando o custo para obtenção de um reforçador aumenta, o consumo desse reforçador diminui e o do outro aumenta. No outro extremo, estão os reforçadores perfeitamente complementares; para esses reforçadores, quando o custo de um deles diminui, seu consumo aumenta e o do outro reforçador também aumenta. Exemplos clássicos (e simplificados) de reforçadores substitutos são Coca-Cola e Pepsi, enquanto que exemplos de reforçadores complementares são comida salgada e água. É importante lembrar que, para analisar a relação de substitutabilidade, é importante que se mantenha a renda do sujeito constante, uma vez que, caso isso não ocorra, as mudanças no consumo de cada reforçador podem ser explicadas por um aumento na possibilidade geral de consumo. Em 
caso de experimentos sobre comportamento operante, uma das formas mais comuns de controlar a renda dos indivíduos é estabelecer um número máximo de respostas por sessão.

Partindo dos dados que mostram que a privação aumenta tanto o consumo de solução de sacarose quanto de correr na roda (Belke, 2004), Belke et al. (2006) procuraram investigar a hipótese de que esses dois reforçadores seriam substitutos e quais seriam as condições em que cada reforçador é mais escolhido. Para isso, realizaram dois experimentos com esquemas concorrentes. O Experimento 1 serviu para investigar as condições em que cada um é mais escolhido e utilizou um esquema concorrente VI 30sVI 30s, em que uma das alternativas consistia em 30s de acesso à roda de atividades e a outra, em liberação de solução de sacarose. Dez ratos Wistar machos foram expostos a esse esquema concorrente em três condições, as quais diferiram em relação à concentração da solução de sacarose: $2,5 \%$; 7,5\% e 12,5\%. Com a concentração 2,5\%, apenas três animais alocaram mais tempo para a solução de sacarose; com 7,5\%, sete animais alocaram mais tempo para a solução de sacarose; com 12,5\%, oito animais alocaram mais tempo para a solução de sacarose. Em relação ao número de respostas, quatro ratos alocaram números similares de resposta quando a concentração foi $2,5 \%$. Cinco animais alocaram mais respostas para a solução de sacarose quando a concentração foi $7,5 \%$ e, para a concentração $12,5 \%$, oito animais alocaram mais respostas para a solução de sacarose. Outro resultado importante foi o de que os animais diminuíram a pausa pós-reforçamento conforme a concentração da solução de sacarose aumentou. Isso permitiu que os animais aumentassem o número de respostas alocadas para a solução de sacarose e mantivessem o número de acessos à roda.

O Experimento 2 (Belke et al., 2006) serviu para investigar a relação de substitutabilidade entre os reforçadores. 15 Long-Evans fêmeas passaram por um 
procedimento em que foram expostas, inicialmente, a um esquema concorrente VR 10VR 10 em que uma das alternativas dava 30s de acesso à roda de atividades e a outra, a 0,1ml de solução de sacarose $7,5 \%$. O número máximo de respostas foi fixado em 600 , a fim de evitar o efeito de renda na variação das taxas. Após isso, foram expostas a duas outras condições: uma em que estava em vigor um esquema VR 20-VR 5 e outra com esquema VR 5-VR 20. Em uma dessas condições, o número de respostas exigido para ter acesso à roda dobrou, enquanto que o número de respostas para solução de sacarose diminuiu pela metade. Na outra condição, ocorreu o inverso. A ordem de apresentação das condições foi balanceada entre os sujeitos. O cálculo do número máximo de respostas para cada uma das condições foi feito multiplicando o número de reforçadores obtidos na primeira condição pelas razões do esquema em vigor em cada condição. Após isso, os animais foram expostos a mesma sequência de esquemas concorrentes, mas agora com acesso à roda produzido pelas duas alternativas. Finalmente, os animais foram expostos, novamente, a mesma sequência de esquemas, mas agora com solução de sacarose produzida em ambas as alternativas. A avaliação das mudanças nas taxas de resposta foi feita por meio da análise dos parâmetros da equação apresentada em Green e Rachlin (1991).

Os experimentadores (Belke et al., 2006) verificaram que, quando o custo para o acesso à roda diminuiu e para solução de sacarose aumentou, o consumo mudou menos do que quando, ao contrário, o custo para acesso à roda aumentou e para solução de sacarose diminuiu. Isso foi interpretado como indicando que a relação entre os dois reforçadores é assimétrica, uma vez que a solução de sacarose serviu como substituta do acesso à roda, mas o acesso à roda foi um reforçador independente da solução de sacarose. É importante salientar que, mesmo o acesso à roda sendo independente da solução de sacarose, houve mudanças no consumo, mas ela foi menor do que a esperada. Outro dado 
importante foi o de que, como esperado, solução de sacarose substituiu solução de sacarose e acesso à roda substituiu correr na roda. No entanto, o grau de substitutabilidade foi maior para solução de sacarose do que para o acesso à roda. A fim de investigar a hipótese de que essa diferença nos graus de substitutabilidade se deveu ao alto número de respostas de alternância entre tentativas, os autores excluíram uma resposta de cada alternativa, e, ao refazerem a análise de substitutabilidade, verificaram que a diferença desapareceu. A relação entre solução de sacarose e acesso à roda se manteve. Os autores também verificaram que as taxas de resposta nos esquemas VR 10-VR 10 com o mesmo reforçador apresentado nas duas alternativas não teve relação com o padrão de resposta quando os esquemas concorrentes apresentavam reforçadores diferentes, uma vez que, com o mesmo reforçador nas duas alternativas, as taxas de resposta e o número de reforçadores obtidos foram maiores quando o reforçador era solução de sacarose. Contudo, na situação em que as alternativas apresentavam reforçadores diferentes, as taxas de resposta e o número de reforçadores obtidos foi similar. Em relação à taxa de correr na roda, em todos os esquemas apresentados, ela sistematicamente aumentou conforme o número de reforçadores obtidos diminuiu. Finalmente, os autores investigaram quais foram os primeiros dez reforçadores obtidos em cada sessão de VR 10-VR10 com reforçadores diferentes em cada alternativa e observaram que os animais escolhiam a solução de sacarose em, aproximadamente $50 \%$ das vezes, indicando que, no início da sessão, eles não apresentam preferência por nenhum dos dois reforçadores.

Em relação às respostas de alternância entre alternativas, os autores (Belke et al., 2006) verificaram que, nas condições de escolha entre solução de sacarose e acesso à roda de atividades, o número desse tipo de resposta foi alto, assim como na condição de escolha entre duas alternativas com acesso à roda. De acordo com os autores, esse dado é importante, porque mostra que os animais mantêm o acesso aos dois reforçadores, mesmo 
que tenham a possibilidade de apresentar preferência exclusiva por uma das alternativas. Esse padrão de respostas seria importante, pois, na natureza, os animais não têm acesso livre aos alimentos e, mesmo comendo, precisam manter as respostas de procurar comida, a fim de evitar o esgotamento das fontes de alimento. Além disso, segundo os autores, o número alto de respostas de alternância poderia ajudar a explicar a manutenção do número de acessos à roda obtidos no Experimento 1, maximizando o número total de reforçadores obtidos.

Tendo em vista os dados sobre o efeito da variação do peso dos animais nas taxas de resposta, de correr na roda e nas pausas pós-reforçamento, (Belke \& Pierce, 2009) procuraram investigar o efeito dessa manipulação na relação de substitutabilidade entre solução de sacarose e acesso à roda descritas por Belke et al. (2006). O procedimento utilizado por Belke e Pierce (2009) foi o mesmo utilizado por Belke et al., (2006), com a diferença de que o responder por correr na roda produziu a possibilidade de realizar 20 voltas e não, como antes, 30s de acesso à roda. 12 Long-Evans fêmeas foram mantidas a $85 \%$ do peso ad-lib (aproximadamente $260 \mathrm{~g}$ ) aprenderam a responder em um esquema concorrente VR 10-VR 10 com solução de sacarose e acesso à roda de atividades como reforçadores. Após o responder se estabilizar, metade dos animais tiveram o peso diminuído para aproximadamente $240 \mathrm{~g}$ e outra metade, o peso aumentado para aproximadamente $320 \mathrm{~g}$. Nessas condições de peso, os animais completaram as mesmas sequências de esquemas concorrentes que em Belke, Pierce e Duncan (2006). Após isso, animais com peso baixo foram alimentados para aumentar de peso até $320 \mathrm{~g}$ e os animais com peso alto tiveram restrição alimentar até diminuir o peso para $240 \mathrm{~g}$. Nessas novas condições de peso, também foram expostos aos mesmos esquemas concorrentes. Os autores verificaram que, nas condições de peso alto (acima do peso ad-lib), os dois reforçadores eram economicamente independentes, enquanto que, nas condições de peso 
baixo, a solução de sacarose substituiu o acesso à roda de atividades, mas o acesso à roda foi independente da solução de sacarose, replicando os dados de Belke et al. (2006). Com base nisso, os autores sugerem que, conforme a privação se intensifica, a relação de substitutabilidade (mesmo que assimétrica) aumenta. Comparando as duas condições de peso, os animais apresentaram maior taxa de respostas - tanto para solução de sacarose quanto para acesso à roda - nas condições de peso baixo do que de peso alto. $\mathrm{O}$ mesmo ocorreu para as taxas de correr na roda, uma vez que os animais correram mais rapidamente nas condições de peso baixo. Comparando o responder por cada reforçador, os animais apresentaram maior taxa de respostas na barra que produzia solução de sacarose nas duas condições de peso. Os autores também verificaram que, quando o peso aumentou, a pausa pós-reforço aumentou muito mais após o correr na roda de atividades do que após o consumo de solução de sacarose. Em relação ao aumento nas taxas de resposta com a variação de peso, contudo, não houve diferença tão pronunciada na mudança das taxas para acesso à roda de atividades (replicando o dado de Belke (2004)).

Dessa forma, então, os estudos de Belke et al. (2006) e Belke e Pierce (2009) sugerem que a privação de alimento afeta, quando apresentados em esquemas concorrentes, tanto o consumo de solução de sacarose quanto de correr na roda, mas o faz de formas distintas. Por isso, a apresentação concorre de correr na roda e de solução de sacarose é uma boa condição para o estudo da privação na desvalorização pelo atraso, uma vez que atende às sugestões de Logue et al. (1988) e Oliveira et al. (2013) de se utilizar como alternativas estímulos diferentemente afetados pela privação.

O objetivo do presente estudo foi investigar o efeito do uso de um regime de privação agudo de alimento (como o utilizado no Experimento 2 de Oliveira et al. (2013)) sobre a desvalorização pelo atraso em situação alomórfica, tendo como estímulos reforçadores em cada alternativa a solução de sacarose e a liberação do acesso à roda de 
atividades. Optou-se por utilizar o regime agudo de privação, porque, com ele o peso dos animais mantém-se o mesmo ao longo experimental, fazendo com que a relação de substitutabilidade permaneça a mesma. Isso é importante para evitar se atribuam à privação possíveis alterações na desvalorização que poderiam ser devidas somente à mudança na relação de substitutabilidade entre os reforçadores.

\section{Método}

\section{Sujeitos}

Seis ratos machos ingênuos (Rattus norvegicus, Wistar, com idade aproximada de 75 dias) provenientes do Instituto de Ciência Biológicas (ICB) da Universidade de São Paulo (USP) foram utilizados como sujeitos experimentais. Os animais foram alocados em três em caixas-viveiro, com microisoladores, de poliuretano transparente (Alesco) com dimensões $25 \mathrm{~cm}$ x $40 \mathrm{~cm}$ x $20 \mathrm{~cm}$, em ciclo diário claro-escuro de 12h, com início da fase de claro às 7:00am. Na primeira semana no biotério, os animais tiveram acesso livre a alimentação. Nas semanas seguintes, os animais receberam uma quantidade de alimento suficiente para mantê-los com, aproximadamente, $90 \%$ do peso ad-lib a fim de aumentar o valor reforçador da solução de sacarose utilizada no treino de pressão à barra. Os animais tiveram acesso ad libitum na caixa-viveiro à água. A partir dos 75 dias, os animais passaram por 18 sessões diárias de 30 minutos nas quais tinham acesso livre à roda de atividades (descrita adiante), a fim de se habituarem ao equipamento e aprender a utilizá-lo.

Ao longo do experimento, os animais passaram por duas condições de privação intercaladas. Em uma delas, receberam o alimento aproximadamente 2 horas antes do início da sessão (Privação Curta). Optou-se por dar o alimento 2 horas antes da sessão 
com base na observação de que os animais levavam aproximadamente 1 hora e 40 minutos para consumir toda a quantidade disponibilizada (aproximadamente $14 \mathrm{~g}$ por animal, ou seja, aproximadamente $28 \mathrm{~g}$ por caixa). Na segunda, receberam o alimento aproximadamente 1 hora depois do término da sessão (Privação Longa). Sendo assim, nas sessões que ocorriam com Privação Curta, os animais passavam pela tarefa tendo consumido o alimento recentemente; nas sessões com Privação Longa, os animais iniciavam a tarefa tendo consumido o alimento aproximadamente 21 horas antes.

\section{Materiais e Equipamento}

Foram utilizadas duas caixas de condicionamento operante Med Associates (32 x $25 \times 21 \mathrm{~cm}$ ). As paredes do fundo da caixa (esquerda e direita) eram feitas de alumínio e o teto e paredes laterais, de acrílico. O piso da caixa era formado por uma grade de aço inoxidável de 0,5 cm de diâmetro, com 1,5 cm de espaçamento entre si. A $6 \mathrm{~cm}$ do piso estão duas barras retráteis, distanciadas uma da outra em $10 \mathrm{~cm}$. A $5 \mathrm{~cm}$ acima de cada barra há uma lâmpada de $2 \mathrm{w}$, que foi iluminada com luz branca (luzes da barra). Na parede oposta à das barras retráteis, havia também uma lâmpada de $2 \mathrm{w}$, iluminada com luz branca, posicionada na parte superior da parede (luz da caixa). Na parede em que estavam as barras, havia um sonalarme com 2,5 KHz de frequência.

Localizado abaixo das barras, distando $5 \mathrm{~cm}$ de cada uma, havia um compartimento retangular, em cuja base estava um buraco circular por meio do qual os animais tinham acesso à solução de sacarose. A solução era disponibilizada por meio de um bebedouro formado por um motor ativado eletronicamente e uma haste de plástico na ponta da qual havia um recipiente metálico. A haste de plástico, quando o bebedouro não estava ativado, ficava abaixada, dentro de um recipiente retangular contendo a solução de sacarose. Ao se ativar o bebedouro, a haste de plástico era erguida e o recipiente de plástico era inserido 
no buraco circular do compartimento retangular acoplado à caixa, dando acesso à solução de sacarose.

Acoplada a cada caixa experimental havia uma roda de atividades Med Associates ENV-042A com 36cm de diâmetro, paredes de acrílico dos dois lados. Os animais tinham acesso à roda por meio de uma abertura de $7 \times 9 \mathrm{~cm}$ na parede oposta à da porta da caixa. Ligado à roda, havia um contador de rotações, que era ativado quando os animais realizavam voltas na roda.

A apresentação dos estímulos e o registro de respostas serão realizados via interface Med-PC ${ }^{\circledR}$ ligada a um computador compatível IBM-PC controlado pelo programa MedPC IV ${ }^{\circledR}$, desenvolvido pela Med. Associates Inc.

\section{Procedimento}

O experimento foi composto de quatro fases que serão descritas com detalhes a seguir. De modo geral, as Fase I, II e III serviram para: ensinar os animais a pressionarem a barra para ter acesso à solução de sacarose; habituar os animais à roda de atividades e permitir que aprendessem à utilizá-la; ensinar os animais a emitirem respostas de pressão à barra (RPB) para ter acesso à roda de atividades. A Fase IV consistiu na tarefa de desvalorização pelo atraso realizada em diferentes condições de privação.

\section{- Fase I: acesso livre à roda e modelagem de pressão à barra}

Essa fase teve início quando os animais completaram 75 dias de idade. Inicialmente, eles passaram por 10 sessões com 30 minutos de duração nas quais tinham acesso livre à roda de atividades. As sessões começavam, aproximadamente, às 9:00am e foram conduzidas às segundas, terças, quintas, sextas e sábados. 
A partir da $10^{\text {a }}$ sessão, quando os animais completaram 89 dias de idade, iniciaram-se as sessões de modelagem da RPB, que ocorreu por meio do reforçamento de aproximações sucessivas. As sessões de modelagem começavam com o acendimento da luz da caixa, da liberação de uma das barras retráteis e do acendimento da luz da barra correspondente à barra liberada. Cada pressão à barra acionava o bebedouro, que permanecia ativado por 5 segundos, dando acesso à $0,01 \mathrm{ml}$ de solução aquosa de sacarose 7,5\%. Foi utilizada a mesma concentração de sacarose de Belke et al. (2006), a fim de permitir a comparação com outro experimento de escolha entre acesso à roda e à solução de sacarose. Além de acionar o bebedouro, cada pressão à barra era seguida do recolhimento da barra e do apagamento da luz da barra. Após 5 segundos, a barra voltava a ser liberada e a luz da barra a ser acessa. A luz da caixa permaneceu acessa ao longo de toda a sessão.

Inicialmente a modelagem ocorreu com a barra que daria acesso à solução de sacarose na Fase IV (esquerda para os animais S1, S3 e S5; direita para S2, S4 e S6). Quando a RPB para essas barras se estabilizou (aproximadamente 3 sessões para cada animal), os animais passaram por modelagem de RPB com a outra barra, que daria acesso à roda de atividades na Fase IV. Os animais foram divididos de forma a que cada dupla da mesma caixa fosse composta por um animal que liberava o acesso à solução de sacarose pressionando a barra da direita e outro, pressionando a barra da esquerda (por exemplo, da primeira dupla faziam parte os animais S1 e S2). Na sessão de modelagem, o acesso à parte da caixa contendo a roda de atividades era restrito por meio de uma placa de metal inserida no espaço entre a caixa experimental e a roda.

Ao longo da modelagem, as sessões de acesso livre continuaram a ser conduzidas. Dessa forma, cada dupla passava, no mesmo dia, por uma sessão de acesso livre e, na sequência, uma sessão de modelagem. Cada sessão de modelagem tinha duração de 30 
minutos. A Fase I acabou quando todos os animais apresentaram RPB estável para as duas barras. Adotou-se um critério para passagem dos animais para Fase II (o mesmo utilizado em Belke, 2004): os animais que apresentassem velocidade média de correr na menor que 16 voltas/minuto (calculada com base no número de voltas da última sessão de acesso livre) não passariam para a fase seguinte. Isso porque, de acordo com os pesquisadores, animais que correm pouco na roda de atividades não aprendem a pressionar a barra para ter acesso à roda. Com base nesse critério, o animal S5 não continuou nas fases seguintes.

\section{- Fase II: VR3 e treino com estímulo sonoro}

As Fases II e III consistiram em uma adaptação do procedimento utilizado por Belke (2004) para ensinar os animais a pressionarem a barra para ter acesso à roda de atividades. A Fase II consistiu em 5 sessões experimentais divididas em duas partes. Na primeira parte, com 30 minutos de duração, a RPB na barra que passaria a produzir acesso à na Fase IV (RPB-roda) passou a ser reforçada com solução de sacarose 7,5\% em um esquema de reforçamento VR3. Assim como na Fase I, cada sessão iniciava com o acendimento das luzes da barra e da caixa e liberação da barra (esquerda para S1 e S3; direita para S2, S4 e S6). A pressão à barra que cumpria o critério do esquema era seguida pela disponibilização da solução de sacarose, recolhimento da barra e apagamento da luz da barra. Após 5 segundos, o bebedouro era desligado, a barra era reapresentada e a luz da barra, acesa. A luz da caixa permanecia acesa ao longo de toda a sessão. Nessa primeira parte, a passagem para a roda de atividades também permaneceu bloqueada. Após a conclusão da primeira parte da sessão, ocorria um intervalo com duração aproximada de 10 segundos, em que o experimentador carregava o programa da parte seguinte e retirava a placa de metal, liberando a passagem para a roda. Essa etapa teve como objetivo manter a RPB em alta frequência. 
A segunda parte da sessão, também com duração de 30 minutos, consistiu em mudar o acesso à roda de livre para um esquema de FT30s e começava com a luz da caixa acesa. Apesar de a passagem para a roda estar livre, a rotação da roda ficava impedida manualmente pelo experimentador. A cada 30 segundos, o sonalarme era ativado por 1 segundo, emitindo um estímulo sonoro, e a rotação da roda era liberada. Após 60 segundos, a rotação voltava a ser restrita manualmente pelo profissional. Ao todo, ocorriam 20 liberações de acesso à roda. O objetivo dessa etapa era parear a apresentação do estímulo sonoro com a liberação da roda.

\section{- Fase III: treino de pressão à barra para liberação do acesso à roda}

Na Fase III, a consequência da RPB-roda deixou de ser a produção de solução de sacarose e passou a ser a liberação do acesso à roda. Ocorreram 6 sessões que iniciavam com o acendimento da luz da caixa, a liberação da barra (esquerda para S1 e S3; direita para S2, S4 e S6) e o acendimento da luz da barra correspondente à barra liberada. A rotação da roda ficou impedida manualmente pelo experimentador. Cada RPB-roda era seguida do acionamento do sonalarme por 1 segundo, recolhimento da barra, apagamento da luz da barra e liberação da rotação da roda. Depois de 60 segundos, a rotação da roda novamente impedida pelo profissional, a barra era reapresentada e a luz da barra, acesa. Assim, a cada RPB-roda, o animal tinha a oportunidade de correr na roda por 60 segundos. A luz da caixa permaneceu acesa ao longo de toda a sessão. Cada sessão da Fase III se encerrava quando eram produzidos 30 reforçadores ou após 1 hora.

\section{- Fase IV: tarefa de desvalorização pelo atraso com duas condições de privação}

A Fase IV consistiu na apresentação da tarefa de desvalorização pelo atraso nas duas condições de privação diferentes. Peterson et al. (2015) discute uma distinção entre as diferentes tarefas de desvalorização, agrupando-as em dois grupos: as tarefas de ajuste 
(como a de Mazur, 1987) e as tarefas sistemáticas (como a de Bradshaw \& Szabadi, 1992 e Evenden \& Ryan, 1996). Nas tarefas sistemáticas, alguma propriedade dos estímulos reforçadores (atraso, magnitude ou probabilidade) são alteradas de acordo com parâmetros fixos (por exemplo, após um certo número de tentativas ou de sessões). Por outro lado, nas tarefas de ajuste, as propriedades do estímulo reforçador são alteradas a depender da escolha feita pelo sujeito (por exemplo, aumentar ou diminuir o atraso de apresentação do estímulo tendo como critério qual escolha o sujeito fez na tentativa anterior).

Optou-se, nesse experimento, por utilizar uma tarefa sistemática, devido a dificuldades em alterar o valor reforçador do correr na roda com base na mudança de sua duração. Como apontam Belke, Pierce e Cathcart (2017), as pesquisas que utilizam o correr na roda como estímulo consequente, procuraram alterar seu valor reforçador por meio da alteração do tempo de acesso à roda para cada resposta emitida. Os resultados de Belke et al. (2017) confirmam a literatura que mostra que, ao contrário do esperado, diminuir o tempo de acesso à roda aumenta a frequência do responder que o produz. No entanto, quando os animais foram expostos às mesmas durações de acesso em condições de privação diferentes, esse efeito não ocorreu e os animais responderam com frequência semelhante em todas as durações.

Tendo em vista que o presente experimento avaliaria a desvalorização pelo atraso em condições de privação diferentes, não seria possível utilizar uma tarefa em que a duração do acesso à roda fosse alterada. Além disso, os resultados do único estudo publicado até o momento da escrita desse trabalho que utilizou o correr na roda como reforçador em uma tarefa de desvalorização pelo atraso (Brinegar, 2007) mostraram que a mudança no atraso de apresentação do correr na roda não alterou as proporções de escolha entre o reforçador imediato e o atrasado. É possível que esse resultado pode se 
dever a questões metodológicas. Porém, dado ser o único a utilizar esse estímulo, não é possível identificar se essa falta de efeito da variação do atraso se deveu a questões metodológicas ou a características específicas do modo como os animais respondem pelo correr na roda.

Levando em consideração esses dados, escolheu-se uma tarefa sistemática de desvalorização pelo atraso, na qual o estímulo sem atraso seria o correr na roda e o estímulo apresentado com atraso seria a solução de sacarose. Considerando o fato de que a tarefa de desvalorização seria realizada em duas condições diferentes de privação, decidiu-se utilizar quatro atrasos diferentes para apresentação da solução de sacarose: 2 segundos, 4 segundos, 8 segundos e 16 segundos (escolhidos com base no experimento de Bradshaw e Szabadi, 1992, que também utilizou uma tarefa sistemática para avaliar o efeito da desvalorização pelo atraso).

As sessões da Fase IV foram realizadas nos 7 dias da semana, começando por volta das 10:30am. Elas eram estruturadas em 4 blocos, compostos, cada um, por 8 tentativas, sendo que as duas primeiras tentativas de cada bloco eram forçadas e as outras 6, livres (cada tipo de tentativa será descrito detalhadamente a seguir). Desse modo, os animais passavam, em cada sessão, por um total de 32 tentativas, das quais 24 eram livres e 8, forçadas.

As tentativas forçadas tinham início com o acendimento da luz da caixa da liberação de uma das barras e do acendimento da sua luz correspondente. A passagem para a roda ficava aberta, mas a rotação era impedida manualmente pelo experimentador. Em uma das duas tentativas forçadas de cada bloco a barra liberada era a que dava acesso à roda de atividades (esquerda para S1 e S3; direita para S2, S4 e S6). Na outra tentativa 
forçada, a barra liberada era a que produzia a solução de sacarose 7,5\%. A ordem em que cada uma das barras era apresentada era aleatória.

$\mathrm{Na}$ tentativa forçada em que a barra apresentada era a que dava acesso à roda de atividades, a pressão à barra era seguida da retração da barra, do apagamento da luz da barra, do acionamento - por 1 segundo - do sonalarme e da liberação da rotação da roda. Depois de 30 segundos, tinha início o intervalo entre tentativas (IET), no qual a luz da caixa era apagada e a rotação da roda impedida pelo experimentador. Dessa forma, os animais tinham 30 segundos de duração do acesso à roda. Essa duração também foi escolhida de acordo com os parâmetros utilizados em Belke et al. (2006), a fim de permitir a comparação entre os resultados. O IET tinha duração de 20 segundos, após os quais tinha início a próxima tentativa. Isso fazia com que a tentativa tivesse duração total de 60 segundos.

A tentativa forçada em que a barra liberada era a que produzia solução de sacarose tinha início também como acendimento da luz da caixa, da luz da barra e da liberação da barra. A rotação da roda era impedida pelo experimentador. A pressão à barra era seguida de apagamento da luz da barra, retração da barra e início da contagem do atraso vigente, após o qual o bebedouro era acionado por 5 segundos, dando acesso à $0,01 \mathrm{ml}$ de solução de sacarose. Terminados os 5 segundos de acesso à solução de sacarose, tinha início o IET, cuja duração era variável, dependendo da duração do atraso vigente, de modo a fazer com que a tentativa tivesse duração total de 60 segundos. Por exemplo, caso o atraso vigente fosse de 4 segundos, o IET teria duração de 60 segundos, menos os 4 segundos do atraso e menos 5 segundos do acesso à solução de sacarose, totalizando 51 segundos. Ao longo do IET, a luz da caixa também era apagada 
Em ambas as tentativas forçadas, os animais tinham 10 segundos para emitir a RPB. Caso os animais não respondessem dentro desse tempo, era registrada uma omissão e tinha início um IET de 50 segundos, no qual a luz da caixa e as luzes da caixa eram apagadas, as barras retraídas e a rotação da roda impedida pelo experimentador.

As tentativas de escolha livre tinham início com o acendimento da luz da caixa, das luzes das barras e da apresentação das duas barras. A passagem para a roda ficava aberta, mas a rotação era impedida manualmente pelo experimentador. A pressão de uma das barras (esquerda para S1 e S3; direita para S2, S4 e S6) era seguida pela retração das duas barras, apagamento das duas luzes das barras, acionamento - por 1 segundo - do sonalarme e liberação da rotação da roda. Após 30 segundos, tinha início o IET, com duração de 20 segundos e durante o qual a luz da caixa era apagada e a rotação da roda impedida pelo experimentador. Concluído o IET tinha início a próxima tentativa. A pressão da outra barra (ordem invertida dos animais em relação à barra anterior) era seguida da retração das duas barras, apagamento das duas luzes das barras e início do atraso em vigência, depois do qual o bebedouro era acionado, dando 5 segundos de acesso à $0,01 \mathrm{ml}$ de solução de sacarose. Concluídos os 5 segundos, tinha início o IET, em que a luz da caixa era apagada. Nesse caso, a duração do IET era calculada da mesma forma que na tentativa forçada de solução de sacarose, considerando o atraso e o tempo de acesso à solução de sacarose de modo a fazer com que a tentativa tivesse duração total de 60 segundos.

Os atrasos na apresentação da solução de sacarose permaneciam em vigência até que fossem cumpridos três critérios (adaptados a partir dos critérios utilizados por Madden, Smith, Brewer, Pinkston e Johnson, 2008), que também utiliza uma tarefa sistemática de desvalorização pelo atraso): (1) vigência mínima de 10 sessões por atraso; (2) ausência de tendências ascendentes ou descendentes na proporção de escolha, nas 
tentativas de escolha livre, da alternativa cujo reforçador era solução de sacarose; (3) a diferença entre a média da proporção de escolha pela alternativa da solução de sacarose (nas tentativas livres) nas 2 últimas sessões se diferenciassem em, no máximo, $8 \%$ da média da proporção de escolha dessa alternativa nas 2 sessões anteriores. A adaptação de critérios em relação aos adotados por Madden et al. (2008) foi que, no estudo citado, o critério 3 consistia em realizar o cálculo comparado as 3 últimas sessões com as 3 sessões anteriores. Optou-se por reduzir o número de sessões de modo a diminuir a duração total do estudo.

A ordem de apresentação dos atrasos levou em conta as condições de privação. Como descrito na subseção "Sujeitos”, os animais passaram por dois regimes de privação distintos. Em um deles, os animais receberam o alimento aproximadamente 2 horas antes do início da sessão (Privação Curta). No segundo, receberam o alimento aproximadamente 1 hora depois do término da sessão (Privação Longa). Desse modo, nas sessões que ocorriam com Privação Curta, os animais passavam pela tarefa tendo consumido o alimento recentemente; nas sessões com Privação Longa, os animais iniciavam a tarefa tendo consumido o alimento aproximadamente 21 horas antes. Cada um dos atrasos foi apresentado duas vezes, uma em que os animais estavam em Privação Curta e na outra, em Privação Longa. Além disso, a ordem de apresentação foi pseudoaleatória de modo a evitar que as durações fossem apresentadas em ordem crescente ou decrescente. Também, evitou-se que duas condições de atraso iguais fossem apresentadas em sequência. Dado que viviam na mesma caixa, os animais de cada dupla eram expostos a uma dada condição de privação ao mesmo tempo, ainda que o atraso fosse diferente. A Tabela $\mathrm{X}$ apresenta a ordem de apresentação dos atrasos e condições de privação para cada sujeito. 
Tabela 1

Ordem de apresentação dos atrasos e das condições de privação para cada sujeito

\begin{tabular}{|c|c|c|c|c|c|c|c|c|}
\hline Sujeito & & & & asos e cond & ões de pri & ıção & & \\
\hline $\mathrm{S} 1$ & $2 \mathrm{~s}(1 \mathrm{~h})$ & $16 \mathrm{~s}(21 \mathrm{~h})$ & $4 \mathrm{~s}(1 \mathrm{~h})$ & $8 s(21 h)$ & $16 \mathrm{~s}(1 \mathrm{~h})$ & $4 \mathrm{~s}(21 \mathrm{~h})$ & $8 \mathrm{~s}(1 \mathrm{~h})$ & $2 \mathrm{~s}(21 \mathrm{~h})$ \\
\hline $\mathrm{S} 2$ & 16s (1h) & $2 \mathrm{~s}(21 \mathrm{~h})$ & 8s (1h) & $4 s(21 h)$ & $2 \mathrm{~s}(1 \mathrm{~h})$ & 8s (21h) & 4s (1h) & $16 \mathrm{~s}(21 \mathrm{~h})$ \\
\hline S3 & $16 \mathrm{~s}(1 \mathrm{~h})$ & $4 s(21 h)$ & 8s (1h) & $2 \mathrm{~s}(21 \mathrm{~h})$ & 4s (1h) & $16 s(21 \mathrm{~h})$ & $2 \mathrm{~s}(1 \mathrm{~h})$ & $8 s(21 h)$ \\
\hline S4 & $2 \mathrm{~s}(1 \mathrm{~h})$ & $8 s(21 h)$ & 4s (1h) & $16 s(21 h)$ & $8 s(1 h)$ & $2 \mathrm{~s}(21 \mathrm{~h})$ & 16s (1h) & $4 s(21 h)$ \\
\hline S6 & $8 s(21 h)$ & $16 \mathrm{~s}(1 \mathrm{~h})$ & $2 \mathrm{~s}(21 \mathrm{~h})$ & $4 s(1 h)$ & $16 \mathrm{~s}(21 \mathrm{~h})$ & $8 \mathrm{~s}(1 \mathrm{~h})$ & $4 s(21 h)$ & $2 \mathrm{~s}(1 \mathrm{~h})$ \\
\hline
\end{tabular}

Nota: em parênteses, as condições de privação, sendo que "1h" indica a condição em que o alimento foi liberado uma hora após a sessão experimental e " 21 ", a condição em que foi liberado 21 horas após a sessão.

\section{Análise de dados}

Para descrever o modo como a mudança no atraso alterou as proporções de escolha entre os reforçadores, foram estimadas as curvas que melhor se ajustaram aos dados obtidos na Fase IV, utilizando o Excel 365. A fim de verificar se a mudança no tempo de atraso para apresentação da solução de sacarose alterou a proporção de escolha de cada alternativa, as proporções de escolha pela solução de sacarose obtidas na Fase IV foram comparadas por meio do teste de Friedman, utilizando o IBM SPSS Statistics 20.

Para avaliar se a alteração na condição de privação modificava o efeito do atraso na proporção de escolha por cada alternativa, comparou-se a área sob a curva obtida para cada condição de privação da Fase IV. A área sob a curva foi calculada do mesmo modo que em Madden et al. (2008): construiu-se um gráfico em que, no eixo das ordenadas, estavam as proporções de escolha pela alternativa da solução de sacarose (variando de 0 a 100\%) e, no eixo das abscissas, os 4 tempos de atraso apresentados; calculou-se, então, a área da figura obtida no gráfico. Quanto maior o valor da área obtida, menor efeito do atraso, ou seja, menor o aumento de escolha pela alternativa imediata conforme o tempo de atraso na apresentação do reforçador atraso aumentou. Comparou-se os valores de área 
para cada condição por meio do Teste de Friedman (utilizando o software IBM SPSS Statistics 20). Também foram comparadas as velocidades obtidas ao longo da Fase IV tanto entre os atrasos na mesma condição de privação quanto entre os mesmos atrasos nas condições de privação diferentes, também utilizando o software IBM SPSS Statistics 20.

\section{Resultados}

Os dados obtidos a partir do procedimento descrito na seção anterior serão apresentados de acordo com as fases experimentais indicadas.

\section{Fase I}

Os animais levaram entre três e quatro sessões para a modelagem da pressão a cada uma das barras. A Tabela 2 apresenta o número total de voltas e a velocidade de corrida (calculada pela razão entre número de voltas e tempo em que a roda ficou disponível). Como descrito na subseção "Sujeitos", o sujeito S5 apresentou velocidade abaixo do critério de inclusão apresentado por Belke et al. (2006), fazendo com que não prosseguisse às fases seguintes.

Tabela 2

Número total de voltas e velocidade média de correr na roda na Fase I

\begin{tabular}{lcc}
\hline Sujeitos & $\mathrm{N}^{\circ}$ de voltas & Velocidade \\
\hline S1 & 722 & 24,07 \\
S2 & 605 & 20,17 \\
S3 & 717 & 23,90 \\
S4 & 799 & 26,63 \\
S5 & 65 & 2,17 \\
S6 & 728 & 24,27 \\
\hline
\end{tabular}

$\underline{\text { Fase II }}$

A Tabela 3 apresenta o número total de respostas nas sessões de VR3 e o número total de voltas nas sessões de FT. O teste de Friedman mostrou que houve diferença 
significativa entre o número de respostas ao longo das sessões, no entanto, o teste de comparações múltiplas não mostrou significância estatística entre as sessões $\left[X^{2}(4)=\right.$ 10,080; $\mathrm{p}<0,05]$. No entanto, a inspeção da tabela mostra que os animais emitiram de forma consistente a resposta de pressão à barra ao longo das sessões.

Tabela 3

Número total de respostas em VR3 e total de voltas em FT30s

\begin{tabular}{lcccccccccc}
\hline & \multicolumn{2}{c}{ Sessão 1 } & \multicolumn{2}{c}{ Sessão 2 } & \multicolumn{2}{c}{ Sessão 3 } & \multicolumn{2}{c}{ Sessão 4 } & \multicolumn{2}{c}{ Sessão 5 } \\
\cline { 2 - 10 } Sujeito & VR3 & FT30s & VR3 & FT30s & VR3 & FT30s & VR3 & FT30s & VR3 & FT30s \\
\hline S1 & 160 & 599 & 317 & 665 & 475 & 702 & 452 & 699 & 547 & 732 \\
S2 & 328 & 613 & 627 & 701 & 823 & 743 & 664 & 785 & 737 & 791 \\
S3 & 464 & 587 & 588 & 644 & 615 & 779 & 683 & 792 & 619 & 806 \\
S4 & 664 & 671 & 692 & 724 & 695 & 706 & 682 & 798 & 633 & 786 \\
S6 & 556 & 622 & 677 & 733 & 659 & 768 & 734 & 805 & 712 & 814 \\
\hline
\end{tabular}

A Tabela 4 apresenta as velocidades ao longo das cinco sessões. A velocidade a partir da Fase II foi calculada por meio da razão entre número de voltas e tempo total em que o acesso à roda esteve liberado. Na Fase I, a roda esteve disponível ao longo de toda a sessão, então o tempo considerado no cálculo da sessão foi a duração da sessão. A partir da Fase II, por exemplo, o tempo utilizado no cálculo da velocidade foi a soma da duração de todos os intervalos em que o acesso à roda foi liberado de acordo com as condições do FT30s. A comparação pelo teste de Friedman mostrou que houve diferença estatisticamente significativa entre as velocidades ao longo das cinco sessões $\left[\mathrm{X}^{2}(4)=\right.$ 17,760; $\mathrm{p}<0,05]$. Isso indica que, apesar de não ter sido encontradas diferenças significativas entre o responder em cada uma das sessões no teste de comparações múltiplas, o correr na roda aumentou, mostrando que não só os animais emitiram respostas de pressão à barra de forma consistente como aumentaram o consumo do correr na roda ao longo das sessões. Isso também indica que o procedimento de pareamento entre liberação da roda com o estímulo sonoro foi eficaz, uma vez que os animais aproveitaram mais as oportunidades de correr na roda. 


\section{Tabela 4}

Velocidade do correr na roda ao longo das sessões da Fase II

\begin{tabular}{lccccc}
\hline Sujeito & Sessão 1 & Sessão 2 & Sessão 3 & Sessão 4 & Sessão 5 \\
\hline S1 & 29,95 & 33,25 & 35,1 & 34,95 & 36,6 \\
S2 & 30,65 & 35,05 & 37,15 & 39,25 & 39,55 \\
S3 & 29,35 & 32,2 & 38,95 & 39,6 & 40,3 \\
S4 & 33,55 & 36,2 & 35,3 & 39,9 & 39,3 \\
S6 & 31,1 & 36,65 & 38,4 & 40,25 & 40,7 \\
\hline
\end{tabular}

Fase III

A Tabela 5 apresenta o número de pressões à barra em cada uma das seis sessões da Fase III, assim como o número total de voltas em cada sessão. A inspeção da tabela mostra que, ao final das seis sessões, todos os sujeitos pressionavam a barra 30 vezes, número máximo possível para cada sessão. Também mostra que houve aumento no número total de voltas, sugerindo que houve não só aumento da pressão à barra como do correr à roda.

Tabela 5

Número de respostas de pressão à barra e de voltas ao longo da Fase III

\begin{tabular}{lcccccccccccc}
\hline & \multicolumn{2}{c}{ Sessão 1 } & \multicolumn{2}{c}{ Sessão 2 } & \multicolumn{2}{c}{ Sessão 3 } & \multicolumn{2}{c}{ Sessão 4 } & \multicolumn{2}{c}{ Sessão 5 } & \multicolumn{2}{c}{ Sessão 6 } \\
\cline { 2 - 11 } Sujeitos & RPB & Voltas & RPB & Voltas & RPB & Voltas & RPB & Voltas & RPB & Voltas & RPB & Voltas \\
\hline S1 & 21 & 618 & 28 & 903 & 29 & 915 & 30 & 1052 & 30 & 1081 & 30 & 1186 \\
S2 & 18 & 506 & 23 & 772 & 28 & 1004 & 27 & 1079 & 30 & 1101 & 30 & 1123 \\
S3 & 21 & 731 & 27 & 986 & 30 & 1027 & 28 & 1018 & 30 & 1105 & 30 & 1098 \\
S4 & 21 & 724 & 27 & 984 & 29 & 1093 & 30 & 1205 & 30 & 1247 & 30 & 1231 \\
S6 & 17 & 606 & 25 & 895 & 24 & 1038 & 29 & 1107 & 30 & 1203 & 30 & 1189 \\
\hline
\end{tabular}

A Tabela 6 apresenta a velocidade ao longo das seis sessões da Fase III. A comparação das velocidades por meio do teste de Friedman mostrou que houve diferença significativa entre as velocidades ao longo das sessões $\left[X^{2}(5)=16,71 ; p<0,05\right]$ e o teste de comparações múltiplas mostrou que as diferenças significativas foram entre as velocidades da primeira e da quinta sessões e da primeira e da sexta sessões. Comparando as Tabelas 3 e 5, verifica-se que a velocidade na primeira sessão da Fase III foi similar à 
da primeira sessão da Fase II. Além disso, os valores nas últimas sessões das duas fases também foram similares. Isso pode ser explicado pelo fato de que tanto na Fase II como na Fase III foi imposta uma nova condição ao correr na roda: na Fase II, o acesso à roda deixou de ser livre e passou a ser liberado a cada 30s; na Fase III, os animais precisavam pressionar a barra para que o correr na roda fosse possível. Nas duas fases, entretanto, houve adaptação às restrições e aumento do correr na roda.

\section{Tabela 6}

Velocidade de correr na roda ao longo da Fase III

\begin{tabular}{lccccc}
\hline Sujeito & Sessão 1 & Sessão 2 & Sessão 3 & Sessão 4 & Sessão 5 \\
\hline S1 & 29,95 & 33,25 & 35,1 & 34,95 & 36,6 \\
S2 & 30,65 & 35,05 & 37,15 & 39,25 & 39,55 \\
S3 & 29,35 & 32,2 & 38,95 & 39,6 & 40,3 \\
S4 & 33,55 & 36,2 & 35,3 & 39,9 & 39,3 \\
S6 & 31,1 & 36,65 & 38,4 & 40,25 & 40,7 \\
\hline
\end{tabular}

\section{$\underline{\text { Fase IV }}$}

A Tabela 7 apresenta o número de sessões que cada sujeito levou para alcançar o critério de estabilidade em cada atraso e a proporção média de escolha pela solução de sacarose nas quatro sessões de estabilidade. Analisando os valores de proporção obtidos para cada atraso, nota-se que houve diminuição da proporção de escolha pela solução de sacarose conforme o atraso aumentou. Comparando-se o número de sessões entre os atrasos para cada uma das condições de privação por meio do Teste de Friedman, verificou-se que o número de sessões não diferiu de forma significativa conforme o atraso aumento tanto para a condição de maior privação (liberação do alimento 1 hora após sessão - 1h) $\left[X^{2}(3)=2,413 ; p>0,05\right]$ quanto para a de maior privação (liberação do alimento 21 horas após sessão $-21 \mathrm{~h})\left[\mathrm{X}^{2}(3)=0,867 ; \mathrm{p}>0,05\right]$. Também não houve diferenças significativas no número de sessões quando se comparou cada atraso nas duas 
condições de privação utilizando o teste de Wilcoxon pareado: $2 \mathrm{~s}(\mathrm{Z}=-0,378 ; \mathrm{p}=0,705)$; $4 s(Z=-0,412 ; p=0,680) ; 8 s(Z=-0,542 ; p=0,496) ; 16 s(Z=-0,680 ; p=0,496)$. Dessa forma, é possível afirmar que os animais levaram um número parecido de sessões para atingir a estabilidade tanto comparando-se os atrasos quanto as condições de privação, o que indica que essas variáveis não influenciaram na dificuldade para alcançar os critérios de estabilidade.

Tabela 7

Número de sessões para atingir critério de estabilidade e proporção de escolha pela solução de sacarose em cada atraso

\begin{tabular}{|c|c|c|c|c|c|c|}
\hline \multirow[b]{3}{*}{ Sujeito } & \multicolumn{6}{|c|}{ Condição de privação } \\
\hline & \multicolumn{3}{|c|}{$1 \mathrm{~h}$} & \multicolumn{3}{|c|}{$21 \mathrm{~h}$} \\
\hline & atraso $(\mathrm{s})$ & $\mathrm{n}^{\circ}$ de sessões & proporção (\%) & atraso (s) & $\mathrm{n}^{\circ}$ de sessões & proporção (\%) \\
\hline \multirow[t]{4}{*}{ S1 } & 2 & 16 & $83,33 \%$ & 2 & 13 & $85,42 \%$ \\
\hline & 4 & 13 & $78,13 \%$ & 4 & 15 & $78,13 \%$ \\
\hline & 8 & 11 & $45,83 \%$ & 8 & 15 & $63,54 \%$ \\
\hline & 16 & 13 & $30,21 \%$ & 16 & 12 & $38,54 \%$ \\
\hline \multirow[t]{4}{*}{ S2 } & 2 & 13 & $94,79 \%$ & 2 & 13 & $93,75 \%$ \\
\hline & 4 & 13 & $82,29 \%$ & 4 & 12 & $90,63 \%$ \\
\hline & 8 & 12 & $63,54 \%$ & 8 & 13 & $79,17 \%$ \\
\hline & 16 & 15 & $35,42 \%$ & 16 & 13 & $58,33 \%$ \\
\hline \multirow[t]{4}{*}{ S3 } & 2 & 13 & $78,13 \%$ & 2 & 11 & $90,63 \%$ \\
\hline & 4 & 14 & $65,63 \%$ & 4 & 13 & $73,96 \%$ \\
\hline & 8 & 13 & $46,88 \%$ & 8 & 10 & $60,42 \%$ \\
\hline & 16 & 12 & $32,29 \%$ & 16 & 15 & $38,54 \%$ \\
\hline \multirow[t]{4}{*}{ S4 } & 2 & 15 & $83,33 \%$ & 2 & 17 & $81,25 \%$ \\
\hline & 4 & 11 & $61,46 \%$ & 4 & 14 & $68,75 \%$ \\
\hline & 8 & 16 & $51,04 \%$ & 8 & 12 & $61,46 \%$ \\
\hline & 16 & 13 & $31,25 \%$ & 16 & 11 & $44,79 \%$ \\
\hline \multirow[t]{4}{*}{ S6 } & 2 & 14 & $90,28 \%$ & 2 & 16 & $89,58 \%$ \\
\hline & 4 & 12 & $71,88 \%$ & 4 & 11 & $84,38 \%$ \\
\hline & 8 & 11 & $57,29 \%$ & 8 & 19 & $46,88 \%$ \\
\hline & 16 & 14 & $39,58 \%$ & 16 & 13 & $31,25 \%$ \\
\hline
\end{tabular}

A Figura 1 apresenta a dispersão das porcentagens de escolha pela solução de sacarose nas quatro últimas sessões de cada sujeito em função do atraso para apresentação 
da solução de sacarose. Cada gráfico representa a dispersão para uma condição de privação. A Tabela 8 apresenta os valores de $\mathrm{R}^{2}$ para cada uma das três funções estimadas em cada uma das duas condições de privação. Nas duas condições, os valores de $\mathrm{R}^{2}$ indicam que a função quadrática foi a que melhor se ajustou aos dados, explicando 85,4\% da variabilidade dos dados na condição de menor privação e 76,9\% dos dados na condição de maior privação. Vale destacar que as três funções se ajustaram de modo menos preciso aos dados na condição de maior privação comparada à de menor privação. $\mathrm{O}$ fato de $\mathrm{a}$ função quadrática ter sido a que mais se ajustou aos dados indica que, como sugere a Tabela 8 , houve diminuição na proporção de escolha pela solução de sacarose, mas o efeito do atraso na mudança da proporção de escolha foi mais intenso quando os atrasos eram menores, diminuindo conforme o atraso aumentou.

Tabela 8

Valores de $R^{2}$ para cada uma das curvas estimadas

\begin{tabular}{lcc}
\hline & \multicolumn{2}{c}{ Condição de privação } \\
\cline { 2 - 3 } & $21 \mathrm{~h}$ & $1 \mathrm{~h}$ \\
\hline Função & $\mathrm{R}^{2}$ & $\mathrm{R}^{2}$ \\
\hline Linear & 0,75270 & 0,80710 \\
Exponencial & 0,75210 & 0,84790 \\
Quadrática & 0,76850 & 0,85350 \\
\hline
\end{tabular}




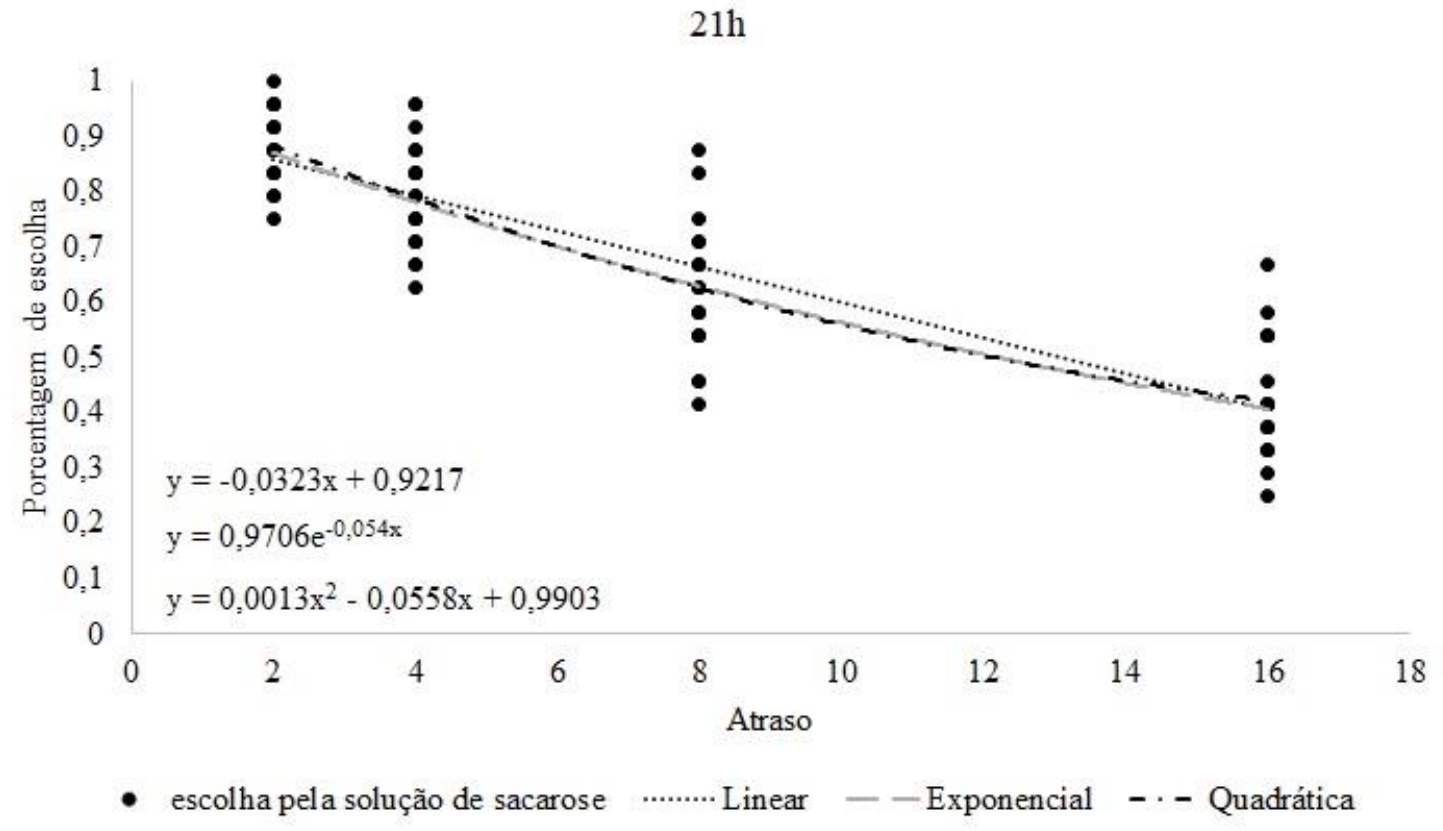

$1 \mathrm{~h}$

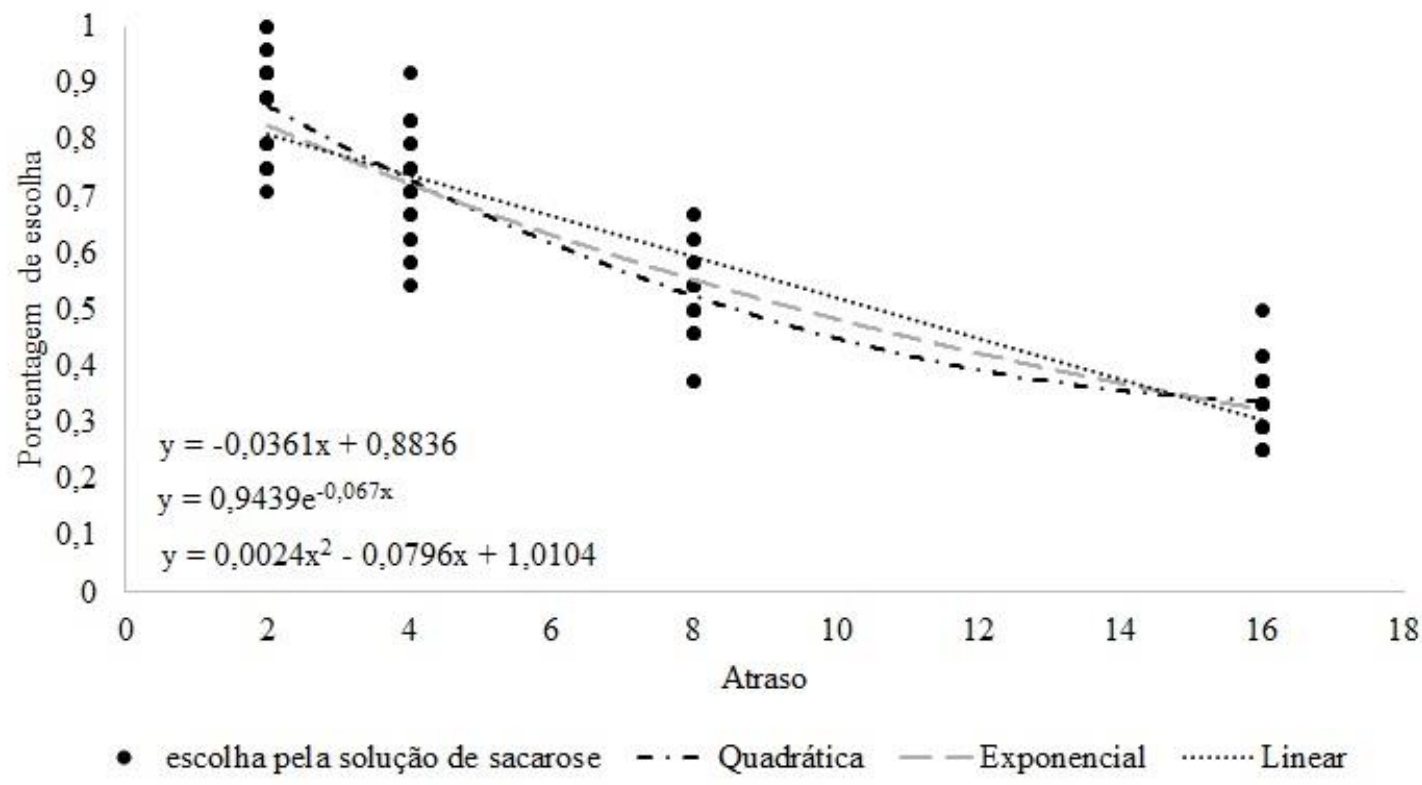

Figura 1. Gráficos de dispersão da proporção de escolha pela solução de sacarose em função do atraso, apresentado em segundos. Também são apresentadas as curvas estimadas a partir dos dados. No gráfico superior, são apresentadas as dispersões para a condição de privação em que o alimento era liberado 21 horas após a sessão experimental e, no gráfico inferior, a condição em que o alimento era liberado uma hora após a sessão. 
A Figura 2 apresenta, para cada sujeito, a média das porcentagens de escolha pela solução de sacarose nas quatro sessões de estabilidade em função do atraso para apresentação do reforçador nas duas condições de privação. Também mostra a reta que representa a média de escolha pela solução de sacarose de todas as sessões de estabilidade do grupo em função do atraso.

A inspeção visual dos gráficos da Figura 2 também indica que houve diminuição da proporção de escolha pela solução de sacarose conforme o atraso para sua apresentação aumentou. A comparação das proporções médias de escolha pela solução de sacarose nas sessões de estabilidade entre os diferentes atrasos por meio do teste de Friedman mostrou que houve diferença significativa entre eles na condição de maior privação $\left[X^{2}(3)=\right.$ $15,00 ; \mathrm{p}<0,05]$. No entanto, o post hoc mostrou que a diferença significativa foi entre as médias do menor atraso (2s) e do maior (16s). O mesmo ocorreu com a comparação entre as médias de escolha na condição de menor privação $\left[X^{2}(3)=15,00 ; p<0,05\right]$; o post hoc também indicou que a diferença significativa foi entre as médias do menor e do maior atraso. Esse dado - junto com o fato de a estimativa da curva feita a partir da dispersão da proporção de escolha ter mostrado que a função quadrática, dentre as curvas estimadas, foi a que melhor se ajustou aos dados - permite afirmar que o atraso alterou a proporção de escolha, uma vez que houve diferença entre a proporção de escolha inicial e a proporção final, mas o fez de maneira pouco intensa, já que nos atrasos iniciais (momento em que, de acordo com a curva estimada, deveria haver maior efeito do atraso) houve pouca diferença entre as proporções obtidas. 


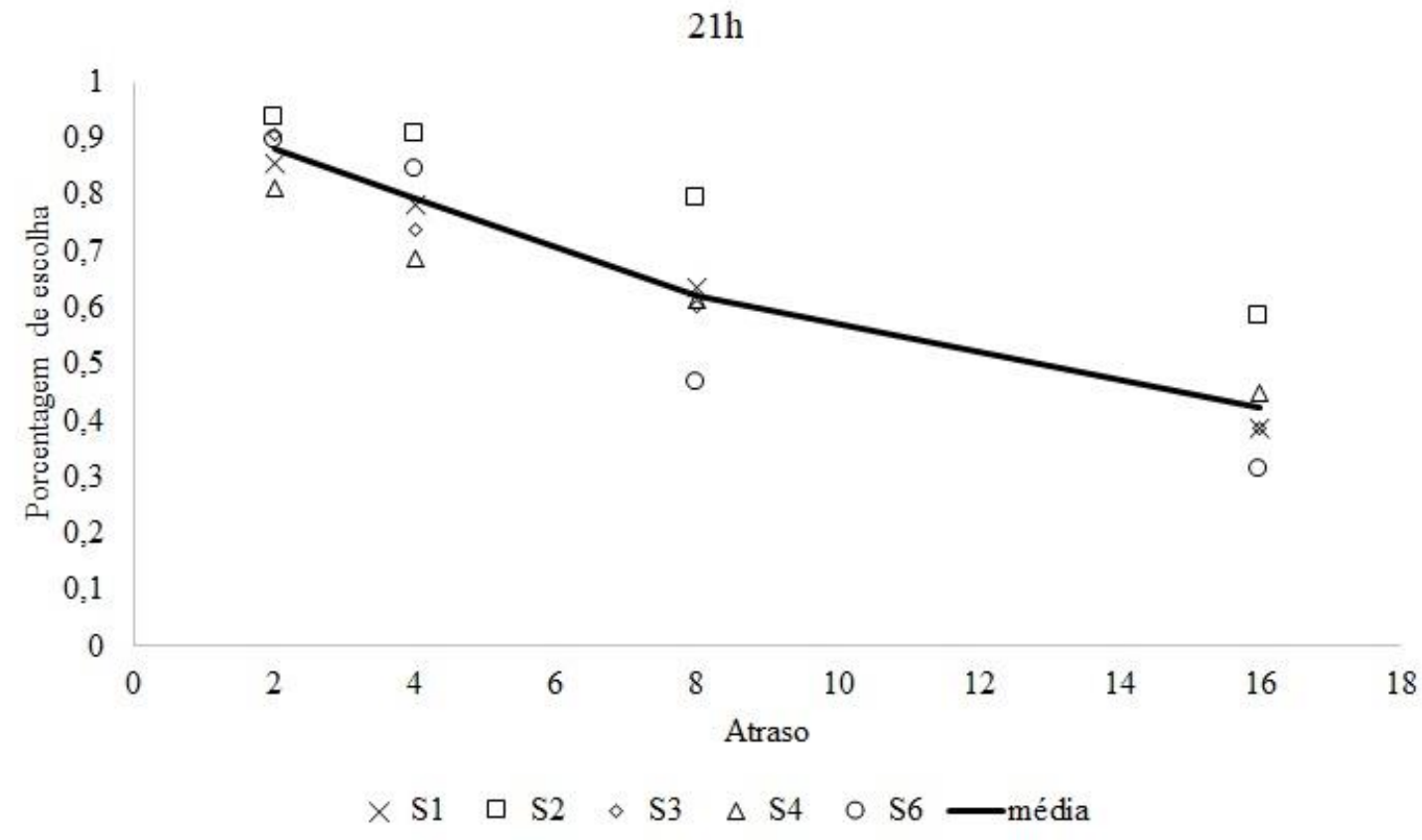

$1 \mathrm{~h}$

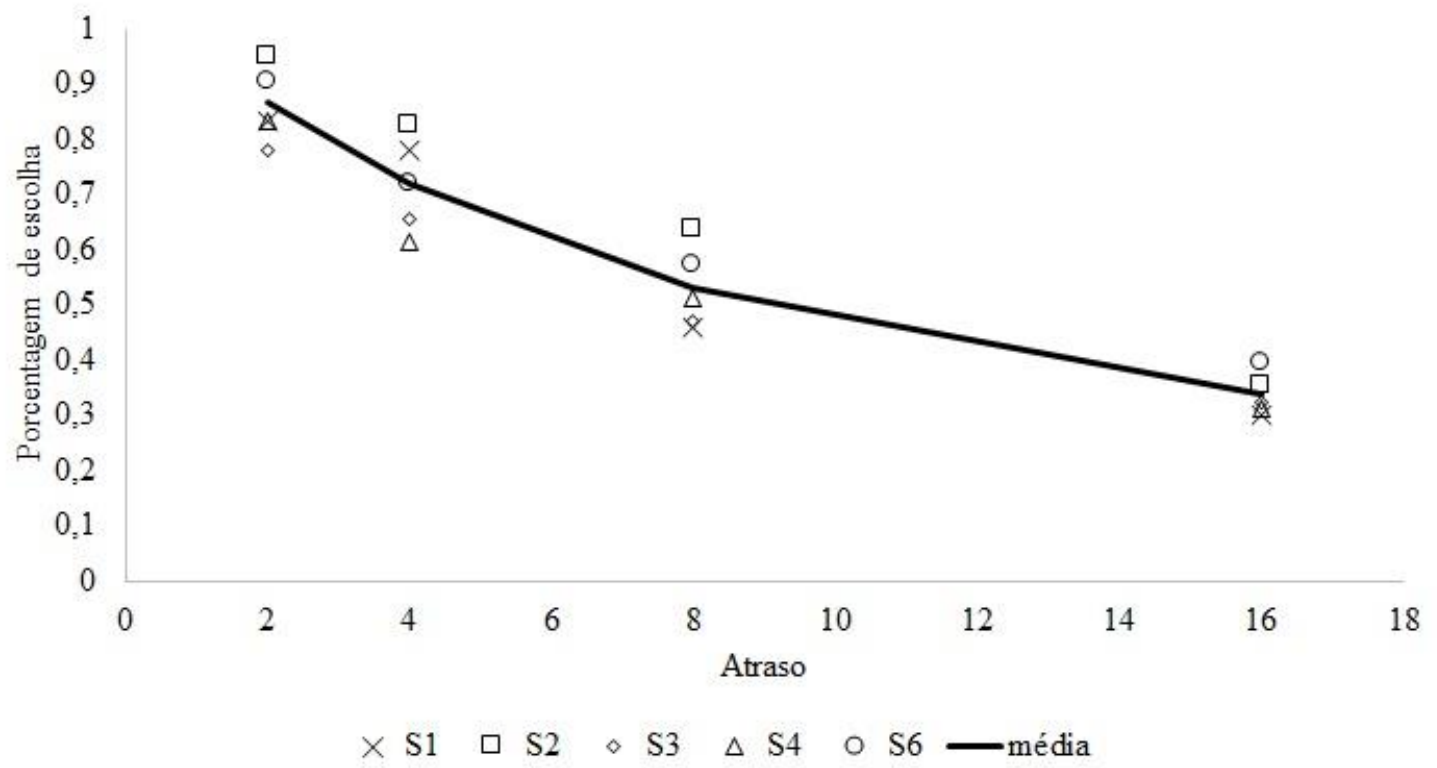

Figura 2. Gráficos com as médias das porcentagens de escolha pela solução de sacarose nas quatro sessões de estabilidade em função do atraso, apresentado em segundos. No gráfico superior, são apresentadas as médias para a condição de privação em que o alimento era liberado 21 horas após a sessão experimental e, no gráfico inferior, a condição em que o alimento era liberado uma hora após a sessão.

Outro dado que permite identificar o efeito do atraso na mudança entre as proporções de escolha é a análise conjunta da Tabela 8 e da Figura 2, a partir das quais é possível afirmar que, para todos os sujeitos, houve reversão de preferência entre as 
alternativas. Isso porque todos os animais começaram escolhendo a solução de sacarose mais de $80 \%$ das vezes em que ela foi apresentada com o menor atraso (exceto o sujeito S3, que escolheu a solução de sacarose $78 \%$ das vezes, na condição de maior privação, quando o atraso era 2s; no entanto, esse valor ainda é alto) e escolheram essa alternativa em menos de $50 \%$ das vezes quando o atraso para sua apresentação foi de 16 s (com exceção do sujeito $\mathrm{S} 2$, que escolheu a solução de sacarose em $58 \%$ das vezes na condição de menor privação). Por outro lado, o fato de que a proporção de escolha pela solução de sacarose no maior atraso ficou, aproximadamente, entre $30 \%$ e $40 \%$ das tentativas sugere que o efeito do atraso foi limitado, uma vez que a preferência por essa alternativa não ficou tão distante da indiferença quanto poderia.

Tabela 9

Valores de área sob a curva para cada condição de privação

\begin{tabular}{lcc}
\hline & \multicolumn{2}{c}{ Condição de privação } \\
\cline { 2 - 3 } & $1 \mathrm{~h}$ & $21 \mathrm{~h}$ \\
\hline Sujeito & AUC & AUC \\
\hline S1 & 713,54 & 855,21 \\
S2 & 864,58 & 1073,96 \\
S3 & 685,42 & 829,17 \\
S4 & 698,96 & 835,42 \\
S6 & 807,99 & 748,96
\end{tabular}

A Tabela 9 apresenta o valor das áreas sob a curva (AUC) obtidas, para cada sujeito nas duas condições de privação, por meio do cálculo da área da figura formada pelas retas de cada sujeito nos gráficos da Figura 2. Comparando-se as áreas sob a curva entre as condições de privação utilizando o teste Wilcoxon pareado verificou-se que não houve diferenças significativas entre as medidas nas duas condições $(Z=-1,753 ; p=$ 0,08). Esse dado sugere que, dentro do intervalo de confiança adotado, o nível de privação não alterou o efeito do atraso na proporção de escolha pela solução de sacarose; no entanto, considerando o p-valor obtido $(0,08)$, é possível argumentar que há possibilidade 
de a privação alterar a desvalorização pelo atraso. Tendo em vista que a maior diferença entre as proporções de escolha foi entre o menor e o maior atraso, é possível levantar a hipótese de que, utilizando atrasos maiores do que os do presente estudo, o efeito da privação poderia ser mais acentuado.

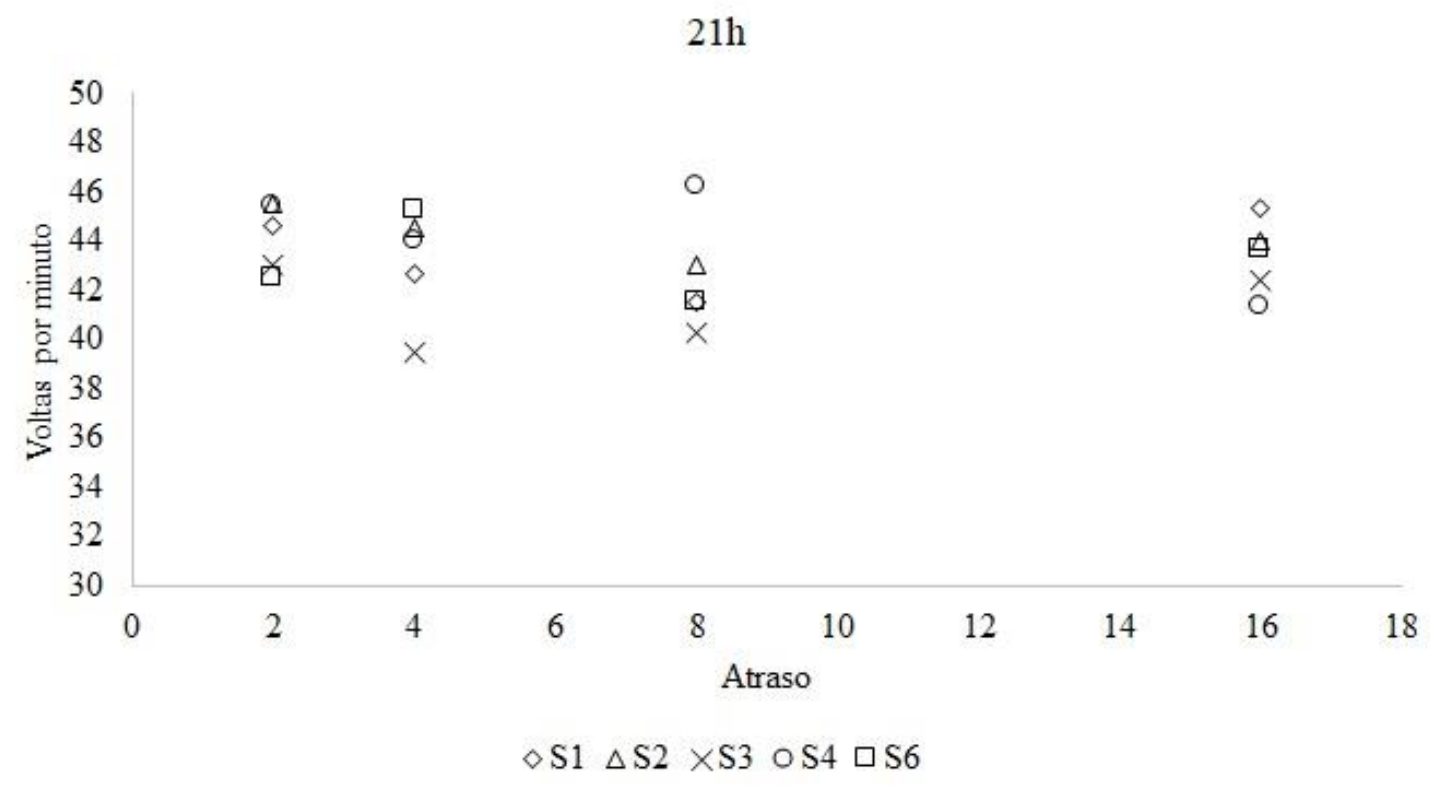

$1 \mathrm{~h}$

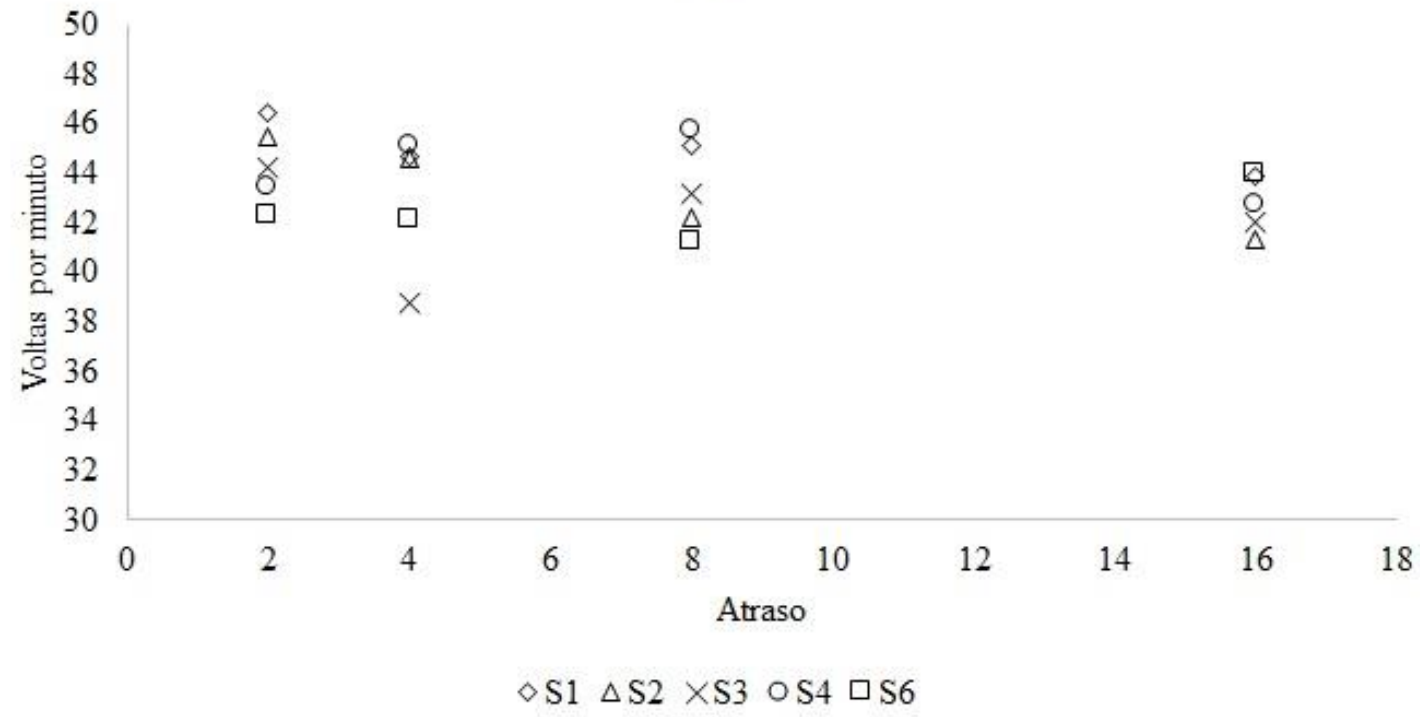

Figura 3. Gráficos apresentado a média das velocidades de correr na roda nas quatro sessões de estabilidade em função de cada atraso, apresentado em segundos. No gráfico superior, são apresentadas as velocidades para a condição de privação em que o alimento era liberado 21 horas após a sessão experimental e, no gráfico inferior, a condição em que o alimento era liberado uma hora após a sessão. 
A Figura 3 apresenta a média, nas quatro sessões de estabilidade, da velocidade do correr na roda em função do atraso. Cada gráfico representa as velocidades em uma das condições de privação. A velocidade na Fase IV foi calculada dividindo o número total de voltas pelo tempo total em que a roda ficou disponível, sendo que esse tempo foi obtido pela multiplicação do intervalo em que a roda ficou disponível em cada pressão à barra (30s) e o número de tentativas em que o animal escolheu a alternativa reforçada com liberação do acesso à roda (incluindo tentativas forçadas e livres). A comparação das velocidades em cada um dos atrasos, para cada condição de privação, feita por meio do teste de Friedman, mostrou que não houve diferença estatisticamente significativa entre elas tanto para a condição de menor privação $\left[\mathrm{X}^{2}(3)=3,00 ; \mathrm{p}>0,05\right]$ quanto para a condição de maior privação $\left[X^{2}(3)=4,20 ; p>0,05\right]$. Comparando-se cada atraso entre as duas condições de privação por meio do teste Wilcoxon pareado, verificou-se que as diferenças entre os atrasos de cada condição não foram estatisticamente significativas: $2 \mathrm{~s}$ $(Z=-0,135 ; p=0,893) ; 4 s(Z=-0,135 ; p=0,893) ; 8 s(Z=-0,405 ; p=0,686) ; 16 s(Z=$ -0,674; $\mathrm{p}=0,500)$. Esse dado sugere que nem o atraso e nem o nível de privação tiveram efeito sobre a velocidade com que os animais correram na roda.

\section{Discussão}

Os objetivos desse estudo foram: (1) investigar o efeito da variação no atraso sob o padrão de escolha entre liberação do correr na roda e solução de sacarose; (2) investigar se a variação no grau de privação de alimento altera o padrão de escolha observado ao longo da variação do atraso para apresentação da solução de sacarose, utilizando um regime de privação agudo.

Os dados apresentados indicam que a variação do atraso para apresentação da solução de sacarose produziu mudanças na proporção de escolha entre os reforçadores. 
Dentre as funções ajustadas aos dados, a que melhor os descreveu foi a função quadrática, cuja curva é uma parábola. Isso sugere que o efeito do atraso, nas condições em que esse par de reforçadores foi apresentado, é mais intenso quando os atrasos são menores, mas diminui conforme os atrasos aumentam. Assim como as curvas hiperbólicas, as parábolas preveem reversão de preferência. Vale ressaltar, no entanto, que as funções foram estimadas a partir das proporções de escolha do reforçador atrasado, sem obtenção de pontos de indiferença. É possível que, utilizando o valor reforçador dos estímulos nos pontos de indiferença ou o valor estimado da variável $k$ (Equações 1 e 2) para esse par de estímulos, outras funções descrevem melhor o efeito do atraso.

A comparação entre as médias da proporção de escolha pela solução de sacarose nas sessões de estabilidade em cada atraso mostrou que houve diferença estatisticamente significativa entre elas. No entanto, as comparações múltiplas mostraram que essa diferença significativa estava entre as proporções no menor e no maior atraso. Uma interpretação possível para esse resultado é a de que o efeito do atraso, apesar de presente, não foi tão pronunciado, uma vez que só ocorreu de forma expressiva, comparando-se as situações extremas de atraso.

Pode-se supor que esse efeito pouco pronunciado do atraso se deva à relação econômica estabelecida entre os estímulos (Belke et al., 2006; Belke \& Pierce, 2009). Como descrito acima, quando esse par de estímulos é apresentado de forma concorrente e os animais estão no mesmo peso que no presente estudo (por volta de 85\%), a relação de substitutabilidade é incompleta, uma vez que aumentos no custo para liberação do acesso à roda fazem com que haja aumento no responder reforçado por liberação de solução de sacarose; por outro lado, aumentos no custo para obtenção de sacarose não produzem aumentos relevantes na escolha por correr na roda. Dessa forma, a solução de 
sacarose é um reforçador substituto para o correr na roda, enquanto que, o correr na roda é um reforçador parcialmente independente da solução de sacarose.

Nos experimentos de Belke e Pierce (2009), a variável manipulada foi o custo para obtenção do reforçador, enquanto que nos experimentos de desvalorização por atraso (como o presente estudo) o custo é mantido constante e o atraso (ou a magnitude) é variado. Então, a hipótese levantada pressupõe que a mesma relação econômica entre os reforçadores observada quando se varia o custo ocorre variando-se o atraso. Uma forma de testar essa hipótese é realizar o mesmo procedimento desse estudo, mudando o peso com que os animais são mantidos. Partindo dos dados de Belke e Pierce (2009), caso a relação econômica entre os estímulos seja a mesma nas duas situações, supõe-se que aumentar o peso dos animais faria com que o efeito do atraso fosse mais evidente, já que, nos experimento citados, quando os animais foram mantidos a $90 \%$ do peso ad-lib, o correr na roda tornou-se substituto da solução de sacarose. Ao contrário, baixando-se o peso dos animais, o efeito do atraso seria ainda menos evidente, pois o correr na roda se tornaria mais independente das condições de obtenção da solução de sacarose.

Outra possível hipótese para explicar esse dado é a de que o uso do correr na roda como um dos estímulos reforçadores atenua o efeito do atraso. Os dados de Brinegar (2007) mostraram que não houve alteração nas proporções de escolha quando as duas alternativas da tarefa de desvalorização apresentaram correr na roda como reforçador, sendo que em todos os valores de atraso e duração do tempo de acesso à roda os animais preferiram o estímulo apresentado com atraso. No entanto, o estudo de Brinegar (2007) não descreve com clareza detalhes importantes do método como quais atrasos foram utilizados e em que ordem foram apresentados. Além disso, como aponta o estudo de Belke et al. (2017), é possível que a alteração da duração do acesso à roda não seja uma forma confiável de mudar o valor reforçador desse estímulo. Desse modo, são necessários 
estudos empíricos melhor estruturados e que manipulam variáveis confiáveis para avaliar o real efeito do atraso quando alguma das alternativas apresente o correr na roda como reforçador.

Uma outra possibilidade de explicação para o baixo efeito do atraso é a de que o critério de estabilidade utilizado não foi rigoroso o suficiente para que as proporções de escolha se adaptassem totalmente ao atraso em vigor. O estudo de Madden et al. (2008) apresentou delineamento experimental parecido com o do presente estudo (uso de tarefa de desvalorização pelo atraso com mudança sistemática do atraso; valores de atraso: 0s; $5 \mathrm{~s} ; 10 \mathrm{~s} ; 15 \mathrm{~s})$ e obteve maiores mudanças nas proporções de escolha conforme o atraso aumentou. Entretanto, uma diferença entre o procedimento desse estudo e o de Madden et al. (2008) foi o critério de estabilidade. Enquanto aqui o atraso era mudado após a diferença entre a média da proporção de escolha nas duas últimas sessões e a das duas sessões anteriores fosse de no máximo 8\%, no estudo de Madden et al. (2008), o critério era o mesmo, mas eram consideradas as médias nas três últimas sessões comparadas com a média nas três sessões anteriores. Isso faz com que, em Madden et al. (2008), os cálculos sejam feitos com base nos dados de seis sessões e, aqui, em quatro sessões. Para testar essa hipótese, é possível utilizar o mesmo procedimento do presente estudo, tornando os critérios de estabilidade mais rigorosos.

Em relação ao segundo objetivo desse estudo, os dados discutidos mostram que não houve diferença na desvalorização comparando-se as duas condições de privação. Esse dado replica os resultados obtidos por Logue e Correal (1985), Logue et al. (1988); Richards et. al. (1997) e Oliveira et al. (2013), mas não corrobora as hipóteses levantadas por Logue et al. (1988) e Oliveira et al. (2013) a respeito dos possíveis efeitos da privação em tarefas de desvalorização com reforçadores diferentes. 
No entanto, é preciso fazer considerações metodológicas antes de se afirmar o quanto os dados do presentem estudo são generalizáveis para outras situações de escolha alomórfica. Primeiro, é possível que a ausência de diferenças no grau de desvalorização pelo atraso se deva aos regimes de privação utilizados. Investigando o efeito da mudança de peso nos padrões de resposta e de correr na roda, Belke (2004) verificaram que nas condições em que os animais estão com maior peso (ou seja, regime de privação menos rigoroso) a velocidade do correr na roda é menor do que nas condições em que os animais estão com menor peso. A comparação, entre as duas condições de privação, das velocidades obtidas no presente estudo mostrou que não houve diferenças significativas entre elas. Isso pode indicar que os regimes de privação utilizados não foram suficientes para provocar mudanças comportamentais nos animais. São necessários outros estudos com o mesmo delineamento experimental, utilizando outras medidas (como latência ou medidas metabólicas) para verificar se os regimes de privação foram muito brandos ou se são suficientes para produzir mudanças no organismo que não influenciam a velocidade e os efeitos da privação.

Vale ressaltar que apenas o estudo de Oliveira et al. (2013), dentre os que investigaram os efeitos da privação, comparou o efeito de regimes de privação crônicos (com mudança de peso) e agudos (sem mudança de peso), não encontrando diferenças significativas. No entanto, a partir do estudo de Oliveira et al. (2013) não é possível afirmar se os dois regimes de privação têm efeitos semelhantes ou se a privação não alterou a desvalorização devido a outras características procedimentais (como o fato de serem escolhas isomórficas). Dessa forma, são necessários estudos empíricos para investigar se, com a mesma tarefa de desvalorização aqui apresentada, regimes crônicos de privação alterariam a desvalorização. Vale retomar, no entanto, os dados de Belke (2009) que mostraram que mudar o peso dos animais também muda a relação econômica 
entre os reforçadores. Assim, seria importante utilizar procedimentos capazes de diferenciar os efeitos da privação e das relações de substitutabilidade na desvalorização.

Considerando as hipóteses levantadas a partir do modelo proposto por Bradshaw e Szabadi (1992), Wogar et al. (1992) e Ho et al. (1997), outra possível explicação para a ausência de efeitos da privação nos resultados aqui discutidos é a de que os parâmetros dos estímulos utilizados estão na faixa em que a privação não alteraria a desvalorização. Retomando as hipóteses dos autores, dentre as variáveis que alteram o efeito da privação sobre a desvalorização são a magnitude absoluta dos estímulos e o atraso com que o estímulo cujo de menor magnitude é apresentado. Desse modo, são necessários experimentos que utilizem outras magnitudes do correr na roda e da solução de sacarose, assim como, outros atrasos na liberação do acesso à roda de atividades.

No entanto, essa proposta de explicação tem entraves metodológicos importantes. Conforme já discutido acima, os dados de Belke et al. (2017) sugerem que a duração do acesso à roda não é uma variável cuja manipulação produza mudanças consistentes no valor reforçador do correr na roda, principalmente quando diferentes durações são reapresentadas aos mesmos sujeitos em regimes de privação distintos. Por isso, não seria recomendado utilizar variações nesse parâmetro como forma de manipular a magnitude do correr na roda. Porém, em um estudo publicado ao longo da condução do experimento do presente estudo, Pierce, Belke e Harris (2018) sugeriram que o número de voltas disponíveis a cada liberação da roda é um parâmetro mais consistente da magnitude do correr na roda. Então, essa seria uma variável possível de ser manipulada em tarefas de desvalorização. Por outro lado, alterar o número de voltas não permitiria que as tentativas tivessem duração fixa, já que os animais podem levar tempos diferentes para completar o mesmo número de voltas. Tentativas com durações diferentes fazem com que variações nas proporções de escolha das alternativas produzam diferentes frequências de liberação 
dos reforçadores e de início das tentativas seguintes, o que pode interferir no efeito do atraso. Entretanto, é importante relembrar que há estudos sobre desvalorização que usam tentativas com duração variável, como o de Belke e Kwan (2000)

Outra consideração metodológica importante diz respeito à manipulação do atraso com que o correr na roda é apresentado. Aqui valem as mesmas considerações feitas a partir dos dados de Brinegar (2007). Os efeitos do atraso no correr na roda não foram sistematicamente estudados, sendo necessários estudos empíricos para verificar como sua variação afeta a escolha quando o correr na roda é apresentado de forma concorrente com outros reforçadores.

A comparação dos estudos de Huskinson et al. (2015) e Huskinson et al. (2016) mostra que, para um mesmo par de estímulos em condição alomórfica, os efeitos do atraso podem mudar, dependendo de quais os estímulos com maiores e menores magnitude e atrasos. Por isso, não é possível generalizar os resultados discutidos para a situação em que o correr na roda fosse apresentado com atraso, no mesmo delineamento utilizado aqui. Então, são necessários estudos que investiguem os efeitos da privação e do atraso com os reforçadores alternados entre as alternativas.

Para avaliar a generalidade dos dados apresentados, é importante discutir algumas limitações metodológicas do presente estudo. A primeira delas diz respeito ao procedimento utilizado para ensinar os animais a pressionarem a barra para liberação do acesso à roda. $\mathrm{O}$ procedimento incluiu uma etapa em que o responder na barra foi inicialmente reforçado com a apresentação de solução de sacarose, antes de passar a ser reforçado com a liberação do acesso a roda. Considerando que a solução de sacarose foi o reforçador da outra alternativa, seria recomendável utilizar, em experimentos futuros, procedimentos diferentes para treinar os animais. O experimento de Belke e Pierce (2009) utiliza um procedimento diferente, em que uma das etapas consiste em parear o som do 
freio automático (equivalente ao som do sonalarme do presente estudo) com a liberação da roda e, em uma etapa seguinte, a barra é apresenta na caixa experimental e a liberação do acesso à roda passa a ser contingente à pressão à barra. Entretanto, os estudos de Belke et al. (2006), Belke e Pirce (2009) e Brinegar (2007) utilizam como sujeitos ratas Wistar fêmeas, as quais, segundo Belke (2009), pressionam a barra espontaneamente (ao contrário dos machos, como os usados no presente experimento), não necessitando que sejam ensinadas a pressionar a barra. Porém, em um estudo sobre esquemas de razão progressiva para apresentação do correr na roda, Cordony, Chow e Boakes (2018) utilizaram fêmeas como sujeitos experimentais e precisaram colocar gotas de água nas barras em diversas sessões do treinamento para fazer com que os animais pressionassem a barra, procedimento sujeito aos mesmos questionamentos do utilizado aqui. Outro detalhe metodológico, além de utilizar fêmeas como sujeitos experimentais, pode ser importante para utilizar procedimentos alternativos para ensinar a resposta de pressão à barra reforçadas com liberação do acesso à roda. O estudo de Cordony et al. (2018) utiliza uma caixa experimental igual à utilizada no presente experimento, em que a roda fica em uma câmara diferente da que são apresentadas as barras, enquanto que os estudos de Belke et al. (2006), Belke e Pierce (2009) e Brinegar (2007) utilizam uma caixa experimental em que as barras e o bebedouro são localizados em uma das paredes da própria câmara da roda. É possível que o fato de as barras estarem em uma câmara diferente da roda faça com que haja atraso entre a pressão da barra e o início do correr na roda, dificultando o aprendizado da contingência em vigor. Portanto, é recomendável que experimentos futuros utilizem a mesma caixa experimental de Belke et al. (2006), Belke e Pierce (2009) e Brinegar (2007) e ratas fêmeas como sujeito.

Outra limitação do presente estudo foi a tarefa de desvalorização utilizada. As considerações a respeito da magnitude e do atraso do correr na roda, demonstraram que 
não seria possível utilizar tarefas de ajuste. No entanto, como aponta Wogar et al. (1992), procedimentos de ajuste permitem obter uma medida direta do atraso (ou da magnitude, em experimentos de ajuste de magnitude) no ponto de indiferença, o que permite uma avaliação mais precisa dos efeitos da privação na desvalorização. Além disso, procedimentos de ajuste permitem obter curvas de indiferença, possibilitando estimar os valores de parâmetros livres dos modelos matemáticos, como as variáveis $k$ e $s$ (Equação 2), as quais são frequentemente utilizadas para avaliar a desvalorização. Como discutido, ainda são necessários estudos empíricos para precisar os efeitos do atraso na escolha pelo correr na roda, mas o estudo de Belke et al. (2018) sugere o número de voltas como possível variável a ser manipulada em procedimentos de ajuste de magnitude.

O número de atrasos utilizados também pode ser considerado uma limitação, já que os efeitos mais significativos do atraso foram vistos comparando-se as proporções no menor e no maior atraso. É possível supor, então, que a utilização de atrasos maiores do que 16s poderia fazer com que os efeitos do atraso fossem detectados de forma mais robusta. No entanto, o estudo de Madden et al. (2008) utilizou o mesmo número de atrasos (com durações semelhantes) e encontrou efeitos robustos do atraso nas proporções de escolha. Caso o efeito pouco intenso do atraso observado nesse experimento não se deva a características do par de estímulos utilizados (discutidas acima), é possível que o número de sujeitos do presente estudo também tenha influenciado nas medidas do efeito do atraso na desvalorização. Portanto, recomenda-se que estudos futuros que usem o mesmo delineamento e o mesmo par de estímulos utilizem mais pontos de atraso e um número maior de sujeitos, a fim de produzir medidas mais precisas dos efeitos do atraso.

\section{Referências}

Ainslie, G. W. (1974). Impulse control in pigeons. Journal of the Experimental Analysis of Behavior, 21(3), 1333221. https://doi.org/10.1901/jeab.1974.21-485 
Ainslie, G. W. (1975). Specious reward: A behavioral theory of impulsiveness and impulse control. Psychological Bulletin, 82(4), 463-496. https://doi.org/10.1037/h0076860

Belke, T. W. (2004). Responding for sucrose and wheel-running reinforcement: Effect of body weight manipulation. Behavioural Processes, 65(2), 189-199. https://doi.org/10.1016/j.beproc.2003.09.006

Belke, T. W., Duncan, I. D., \& Pierce, D. W. (2006). Reinforcement Value and Substitutability of Sucrose and Wheel Running: Implications for Activity Anorexia. Journal of the Experimental Analysis of Behavior, 86(2), 131-158. https://doi.org/10.1901/jeab.2006.98-05

Belke, T. W., \& Kwan, T. Y. (2000). The Effect of Changes in Availability on Food Selection at Different Levels of Deprivation. The Psychological Record, 50(3), 529541. https://doi.org/10.1007/BF03395369

Belke, T. W., \& Pierce, W. D. (2009). Body weight manipulation, reinforcement value and choice between sucrose and wheel running: A behavioral economic analysis. Behavioural Processes, $\quad$ 80(2), 147-156. https://doi.org/10.1016/j.beproc.2008.11.006

Belke, T. W., Pierce, W. D., \& Cathcart, I. E. A. (2017). Duration of wheel-running reinforcement: Effects on reinforcement value and motivation in free-feeding and food-deprived rats. Learning and Motivation, 60(July), 1-9. https://doi.org/10.1016/j.lmot.2017.10.001

Bickel, W. K., Landes, R. D., Rock, L., Christensen, D. R., Jackson, L., \& Redish, A. D. (2011). Single- and cross-commodity discounting among cocaine addicts: the commodity and its temporal location determine discounting rate. Psychopharmacology, 217(2), 177-187. https://doi.org/10.1007/s00213-011-2272x.Single-

Bradshaw, C. M., \& Szabadi, E. (1992). Choice Between Delayed Reinforcers in a Discrete-trials Schedule: The Effect of Deprivation Level. The Quarterly Journal of Experimental Psychology Section B, 44(1), 1-16. https://doi.org/10.1080/02724999208250599

Brinegar, J. L. (2007). Self-Control Choices Using Running Reinforcement By. The University of Montana.

Christensen-Szalanski, J. J. J., Goldberg, A. D., Anderson, M. E., \& Mitchell, T. R. (1980). Deprivation, delay of reinforcement, and the selection of behavioural strategies. Animal Behaviour, 28(2), 341-346. https://doi.org/10.1016/S00033472(80)80042-X

Cordony, M. B. L., Chow, J. Y. L., \& Boakes, R. A. (2018). Motivation to run measured by progressive ratio tests: Failure to support the addiction hypothesis for rats. Learning and Behavior, 47(2), 131-140. https://doi.org/10.3758/s13420-018-03488

Evenden, J. L., \& Ryan, C. N. (1996). The pharmacology of impulsive behaviour in rats: The effects of drugs on response choice with varying delays of reinforcement. 
Psychopharmacology, 128(2), 161-170. https://doi.org/10.1007/s002130050121

Gonçalves, F. L. (2005). Desvalorização pelo atraso em situações apetitivas e aversivas. (Tese de doutorado, Instituto de Psicologia, Universidade de São Paulo). Recuperado de www.teses.usp.br.

Green, L., \& Freed, D. E. (1993). The substitutability of reinforcers. Journal of the Experimental Analysis of Behavior, 60(1), 141-158. https://doi.org/10.1901/jeab.1993.60-141

Green, L., \& Myerson, J. (2004). A discounting framework for choice with delayed and probabilistic rewards. Psychological Bulletin, 130(5), 769-792. https://doi.org/10.1037/0033-2909.130.5.769

Green, L., Myerson, J., \& Vanderveldt, A. (2014). Delay and Probability Discounting. In F. K. McSweeney \& E. S. Murphy (Eds.), The Wiley Blackwell Handbook of Operant and Classical Conditioning. https://doi.org/10.1002/9781118468135

Herrnstein, R. J. (1970). On the Law of Effect. Journal of the Experimental Analysis of Behavior, 13(2), 243-266. https://doi.org/10.1901/jeab.1970.13-243

Herrnstein, R.J. (1981). Self-control as response strength. In C.M. Bradshaw, E. Szabadi, \& C.F. Lowe (Eds.), Quantification of steady-state operant behaviour (pp. 3-20). Amsterdam: Elsevier/North-Holland.

Ho, M., Wogar, M. A., Bradshaw, C. M., \& Szabadi, E. (1997). Choice between Delayed Reinforcers: Interaction between Delay and Deprivation Level. Quarterly Journal of Experimental Psychology Section B: Comparative and Physiological Psychology, 50(3), 193-202. https://doi.org/10.1080/713932652

Huskinson, S. L., Myerson, J., Green, L., Rowlett, J. K., Woolverton, W. L., \& Freeman, K. B. (2016). Shallow discounting of delayed cocaine by male rhesus monkeys when immediate food is the choice alternative. Experimental and Clinical Psychopharmacology, 24(6), 456-463. https://doi.org/10.1037/pha0000098

Huskinson, S. L., Woolverton, W. L., Green, L., Myerson, J., \& Freeman, K. B. (2015). Delay discounting of food by rhesus monkeys: Cocaine and food choice in isomorphic and allomorphic situations. Experimental and Clinical Psychopharmacology, 23(3), 184-193. https://doi.org/10.1037/pha0000015

Logue, A. W., Chavarro, A., Rachlin, H., \& Reeder, R. W. (1988). Impulsiveness in pigeons living in the experimental chamber. Animal Learning \& Behavior, 16(1), 31-39. https://doi.org/10.3758/BF03209040

Logue, A. W., \& Peña-Correal, T. E. (1985). The effect of food deprivation on selfcontrol. Behavioural Processes, 10(4), 355-368. https://doi.org/10.1016/03766357(85)90036-1

Madden, G. J., Smith, N. G., Brewer, A. T., Pinkston, J. W., \& Johnson, P. S. (2008). Steady-State Assessment of Impulsive Choice in Lewis and Fischer 344 Rats: Between-Condition Delay Manipulations. Journal of the Experimental Analysis of Behavior, 90(3), 333-344. https://doi.org/10.1901/jeab.2008.90-333

Mitchell, J. E., Agras, W. S., Wilson, G. T., Halmi, K., Kraemer, H., \& Crow, S. (2004). 
A trial of a relapse prevention strategy in women with bulimia nervosa who respond to cognitive-behavior therapy. The International Journal of Eating Disorders, 35(4), 549-555. https://doi.org/10.1002/eat.10265

Odum, A. L. (2011). Delay Discounting: I'm a k, You're a k. Journal of the Experimental Analysis of Behavior, 96(3), 427-439. https://doi.org/10.1901/jeab.2011.96-423

Oliveira, L., Calvert, A. L., Green, L., \& Myerson, J. (2013). Level of deprivation does not affect degree of discounting in pigeons. Learning and Behavior, 41(2), 148-158. https://doi.org/10.3758/s13420-012-0092-4

Peterson, J. R., Hill, C. C., \& Kirkpatrick, K. (2015). Measurement of impulsive choice in rats: Same- and alternate-form test-retest reliability and temporal tracking. Journal of the Experimental Analysis of Behavior, 103(1), 166-179. https://doi.org/10.1002/jeab.124

Pierce, W. D., Belke, T. W., \& Harris, A. F. (2018). Instrumental lever pressing for wheel running is a bitonic function of wheel revolutions per reinforcement: Effects of constraint and automatic reinforcement. Learning and Motivation, 64(March), 9-17. https://doi.org/10.1016/j.lmot.2018.07.001

Rachlin, H. (1974). Self-Control. Behaviorism, 2(1), 94-107. Retrieved from http://www.jstor.org/stable/27758811

Rachlin, H., \& Green, L. (1972). Commitment, Choice and Self-Control. Journal of the Experimental Analysis of Behavior, 17(1), 15-22. https://doi.org/10.1901/jeab.1972.17-15

Richards, J. B., Mitchell, S. H., de Wit, H., \& Seiden, L. S. (1997). Determination of discount functions in rats with an adjusting-amount procedure. Journal of the Experimental Analysis of Behavior, 67(3), 353-366. https://doi.org/10.1901/jeab.1997.67-353

Vanderveldt, A., Oliveira, L., \& Green, L. (2016). Delay discounting: Pigeon, rat, humandoes it matter? Journal of Experimental Psychology: Animal Learning and Cognition, 42(2), 141-162. https://doi.org/10.1037/xan0000097

Wogar, M. A., Bradshaw, C. M., \& Szabadi, E. (1992). Choice Between Delayed Reinforcers in an Adjusting-delay Schedule: The Effects of Absolute Reinforcer Size and Deprivation Level. The Quarterly Journal of Experimental Psychology Section B, 45(1), 1-13. https://doi.org/10.1080/14640749208401021

Yoon, J. H., Higgins, S. T., Bradstreet, M. P., Badger, G. J., \& Thomas, C. S. (2009). Changes in the relative reinforcing effects of cigarette smoking as a function of initial abstinence. Psychopharmacology, 205(2), 305-318. https://doi.org/10.1007/s00213-009-1541-4 


\section{Anexos}

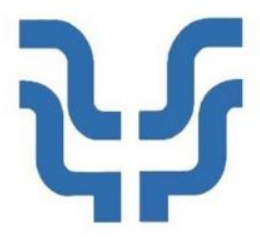

\section{INSTITUTO DE PSICOLOGIA}

www.ip.usp.br
Comissão de Ética no Uso de Animais

Universidade de São Paulo

\section{CERTIFICADO}

Certificamos que a proposta intitulada "Efeito da privação de alimento no grau de desvalorização pelo atraso avaliada em escolha alomórfica", protocolada sob o CEUA no 8963100418, sob a responsabilidade de Profa. Dra. Miriam Garcia Mijares e equipe; Guilherme do Espirito Santo Paes - que envolve a produção, manutenção e/ou utilização de animais pertencentes ao filo Chordata, subfilo Vertebrata (exceto o homem), para fins de pesquisa científica ou ensino - está de acordo com os preceitos da Lei 11.794 de 8 de outubro de 2008, com o Decreto 6.899 de 15 de julho de 2009, bem como com as normas editadas pelo Conselho Nacional de Controle da Experimentação Animal (CONCEA), e foi aprovada pela Comissão de Ética no Uso de Animais da Instituto de Psicologia da Universidade de São Paulo (CEUA/IPUSP) na reunião de 17/09/2018.

We certify that the proposal "Effect of food deprivation on the degree of delay discounting evaluated in allomorphic choice", utilizing 6 Heterogenics rats ( 6 males), protocol number CEUA 8963100418, under the responsibility of Profa. Dra. Miriam Garcia Mijares and team; Guilherme do Espirito Santo Paes - which involves the production, maintenance and/or use of animals belonging to the phylum Chordata, subphylum Vertebrata (except human beings), for scientific research purposes or teaching - is in accordance with Law 11.794 of October 8, 2008, Decree 6899 of July 15, 2009, as well as with the rules issued by the National Council for Control of Animal Experimentation (CONCEA), and was approved by the Ethic Committee on Animal Use of the Psychology Institute - Universidade de São Paulo (CEUA/IPUSP) in the meeting of 09/17/2018.

Finalidade da Proposta: Pesquisa (Acadêmica)

Vigência da Proposta: de 06/2017 a 09/2017_ Área: Psicologia Experimental

Origem: Biotério do Instituto de Ciências Biomédicas da USP

Espécie: Ratos heterogênicos sexo: Machos $\quad$ idade: 30 a 45 dias $\quad \mathrm{N}$ : 6

Linhagem: Wistar $\quad$ Peso: 250 a $350 \mathrm{~g}$

O procedimento tradicional de desvalorização pelo atraso consiste em apresentar ao sujeito uma situação de escolha com duas alternativas, uma que dá acesso a um reforçador pequeno mas sem atraso e outra que dá acesso a um reforçador maior mas após um período variável de atraso. Ambas as alternativas apresentam o mesmo tipo de reforçador. 0 procedimento de escolha alomórfica tem a mesma estrutura de escolha com duas alternativas que envolvem atrasos diferentes, mas difere no fato de que cada uma das alternativas dá acesso a reforçadores de tipos diferentes. 0 efeito da privação na desvalorização pelo atraso avaliada com o procedimento tradicional tem sido controverso em animais humanos e não-humanos, sendo que os experimentos mais recentes com animais não-humanos sugere que diferentes graus e regimes de privação não alteram a influência do atraso no valor reforçador do estímulo apresentado com atraso. A hipótese explicativa para esse dado é a de que a privação altera igualmente o valor reforçador das duas alternativas, o que faz com que o padrão de escolha não difira daquele observado em condição sem privação. Por outro lado, em situações de de escolha alomórfica, a privação de um dos estímulos apresentados alteraria de forma diferente o valor reforçador dos estímulos reforçadores apresentados em cada alternativa, fazendo com que o efeito do atraso seja modulado pelo grau de privação. Para investigar essa hipótese, o estudo aqui apresentado irá utilizar um procedimento de escolha alomórfica em que uma das alternativas dará acesso a uma roda de atividades acoplada à caixa experimental e a outra dará acesso à uma solução de água e 10\% de sacarose. Serão obtidos 2 pontos de indiferença para 5 atrasos no acesso à solução de sacarose $(3 \mathrm{~s}, 5 \mathrm{~s}, 10 \mathrm{~s}, 20 \mathrm{~s}, 40 \mathrm{~s})$; o primeiro será obtido com os sujeitos privados de alimento por 1 hora antes da sessão experimental e o outro, com os sujeitos privados por 23 horas antes da sessão experimental. Serão comparados os pontos de indiferença obtidos na condição de privação de 1 hora com os obtidos na condição de privação e 23 horas a fim de verificar se a diferença no grau de privação de cada uma das condições altera a frequência de escolha da alternativa que envolve atraso na apresentação do estímulo reforçador.

Local do experimento: Sala de experimentação C8 do Bloco A do Instituto de Psicologia

São Paulo, 30 de julho de 2019 


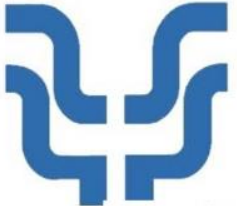

INSTITUTO DE PSICOLOGIA

www.ip.usp.br

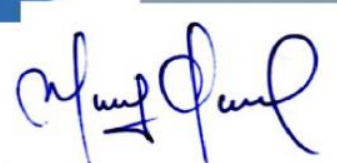

Profa.Dra. Miriam Garcia Mijares

Presidente em Exercício da Comissão de Ética no Uso de Animais Instituto de Psicologia da Universidade de São Paulo
Comissão de Ética no Uso de Animais

Universidade de São Paulo

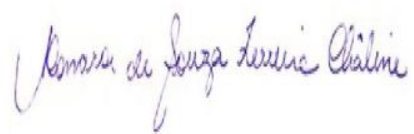

Profa Dra Ronara de Siuza Ferreira Châline Vice Presidente

Instituto de Psicologia da Universidade de São Paulo 